\section{(1)}

CrossMark

\title{
Use of exercise testing in the evaluation of interventional efficacy: an official ERS statement
}

\begin{abstract}
Luis Puente-Maestu ${ }^{1,2,3}$, Paolo Palange ${ }^{4}$, Richard Casaburi ${ }^{5}$, Pierantonio Laveneziana ${ }^{6,7}$, François Maltais ${ }^{8}$, J. Alberto Neder ${ }^{9,10}$, Denis E. O'Donnell ${ }^{11}$, Paolo Onorati ${ }^{4,12}$, Janos Porszasz ${ }^{5}$, Roberto Rabinovich ${ }^{13}$, Harry B. Rossiter ${ }^{5,14}$, Sally Singh ${ }^{15}$, Thierry Troosters ${ }^{16,17}$ and Susan Ward ${ }^{18}$

Affiliations: 'Servicio de Neumología del Hospital Universitario Gregorio Marañón, Madrid, Spain. ${ }^{2}$ Instituto de Investigación Sanitaria Gregorio Marañón, Madrid, Spain. ${ }^{3}$ Facultad de Medicina de la Universidad Complutense de Madrid, Madrid, Spain. "Dipartimento di Sanità Pubblica e Malattie Infettive, Sapienza Università di Roma, Rome, Italy. ${ }^{5}$ Rehabilitation Clinical Trials Center, Division of Pulmonary and Critical Care Physiology and Medicine, Los Angeles Biomedical Research Institute at Harbor-UCLA Medical Center, Torrance, CA, USA. 'UMRS1158 Neurophysiologie Respiratoire Expérimentale et Clinique, Sorbonne Universités, UPMC Université Paris 06, INSERM, Paris, France. ${ }^{7}$ Service des Explorations Fonctionnelles de la Respiration, de l'Exercice et de la Dyspnée, Assistance Publique-Hôpitaux de Paris (AP-HP), Groupe Hospitalier Pitié-Salpêtrière Charles Foix, Paris, France. ${ }^{8}$ Institut Universitaire Cardiologie et de Pneumologie de Québec, Université Laval, Québec, QC, Canada. ${ }^{9}$ Laboratory of Clinical Exercise Physiology, Division of Respiratory and Critical Care Medicine, Queen's University and Kingston General Hospital, Kingston, ON, Canada. ${ }^{10}$ Division of Respirology, Clinical Exercise Physiology Unit, Federal University of Sao Paulo, Sao Paulo, Brazil. ${ }^{11}$ Respiratory Investigation Unit, Division of Respiratory and Critical Care Medicine, Queen's University and Kingston General Hospital, Kingston, ON, Canada. ${ }^{12}$ Ospedale Civile di Alghero, ASL1-Sassari, Alghero (SS), Italy. ${ }^{13}$ ELEGI Colt Laboratory, Centre for Inflammation Research, The Queen`s Medical Research Institute, University of Edinburgh, Edinburgh, UK. ${ }^{14}$ Faculty of Biological Sciences, University of Leeds, Leeds, UK. ${ }^{15}$ Centre for Exercise and Rehabilitation Science, Glenfield Hospital, University Hospitals of Leciester NHS Trust, Leciester, UK. ${ }^{16}$ Dept of Rehabilitation Sciences, KU Leuven, Leuven, Belgium. ${ }^{17}$ Respiratory Rehabilitation Division, University Hospital Gasthuisberg, Leuven, Belgium. ${ }^{18}$ Human BioEnergetics Research Centre, Crickhowell, UK.
\end{abstract}

Correspondence: Luis Puente-Maestu, Hospital General Universitario Gregorio Marañón, Servicio de Neumología, c/ Doctor Ezquerdo 46, 28007 Madrid, Spain. E-mail: Ipuentedsepar.es

ABSTRACT This document reviews 1) the measurement properties of commonly used exercise tests in patients with chronic respiratory diseases and 2) published studies on their utilty and/or evaluation obtained from MEDLINE and Cochrane Library searches between 1990 and March 2015.

Exercise tests are reliable and consistently responsive to rehabilitative and pharmacological interventions. Thresholds for clinically important changes in performance are available for several tests. In pulmonary arterial hypertension, the 6-min walk test (6MWT), peak oxygen uptake and ventilation/carbon dioxide output indices appear to be the variables most responsive to vasodilators. While bronchodilators do not always show clinically relevant effects in chronic obstructive pulmonary disease, high-intensity constant work-rate (endurance) tests (CWRET) are considerably more responsive than incremental exercise tests and 6MWTs. High-intensity CWRETs need to be standardised to reduce interindividual variability. Additional physiological information and responsiveness can be obtained from isotime measurements, particularly of inspiratory capacity and dyspnoea. Less evidence is available for the endurance shuttle walk test. Although the incremental shuttle walk test and 6MWT are reliable and less expensive than cardiopulmonary exercise testing, two repetitions are needed at baseline. All exercise tests are safe when recommended precautions are followed, with evidence suggesting that no test is safer than others.

@ERSpublications

A review of exercise testing to evaluate interventions aimed to improve exercise tolerance in respiratory patients http://ow.ly/U37mQ

This article has supplementary material available from erj.ersjournals.com

Received: May 122015 | Accepted after revision: Sept 142015 | First published online: Jan 212016

Conflict of interest: Disclosures can be found alongside the online version of this article at erj.ersjournals.com

Copyright CERS 2016 


\section{Introduction}

From an evidence-based perspective, performance during standardised exercise tests (both laboratory and field tests) with associated pathophysiological responses are of considerable importance in the multidimensional evaluation of most respiratory diseases $[1,2]$. Exercise testing is fundamental for the accurate quantification of cardiorespiratory fitness and for identifying mechanisms underlying exercise intolerance, particularly with regard to activities having a significant aerobic-energetic requirement $[3,4]$. However, none of the primary test formats could reasonably be regarded as stressing purely "aerobic" mechanisms; their symptom-limited character also confers varying degrees of "anaerobiosis". Several indices of physiological response relate independently to major clinical outcomes such as survival and hospital admissions, thus allowing considerable improvement in prognostic stratification $[1,5-12]$.

Aware of its importance, regulatory agencies such as the United States Food and Drug Administration (FDA) and European Medicines Agency/Committee for Medicinal Products for Human Use have issued (in draft or final form) guidelines for the pharmaceutical industry recognising exercise testing as an efficacy end-point for interventions in chronic obstructive pulmonary disease (COPD) and pulmonary arterial hypertension (PAH) [13-15]. Direct assessment of the effects of interventions on exercise performance is also likely to be relevant for other chronic respiratory conditions.

There is now a substantial body of evidence relating to the value of different exercise indices in assessing the effects of therapeutic interventions in respiratory diseases. In 2012, the scientific committee of the European Respiratory Society (ERS) approved the constitution of a task force whose goal was to review comprehensively the value and limitations of different exercise indices as outcomes for therapeutic interventions, based upon current scientific evidence. This document summarises the work of the task force.

The primary target audience comprises clinicians and researchers who use exercise testing in the evaluation of interventions. The task force agreed that only indices with demonstrable impact on intervention-related improvement in exercise tolerance would be addressed. Aspects such as quality control, laboratory requisites and safety measures are not included, as these are well covered elsewhere. Some tests, such as the sit-to-stand test and the gait-speed test are not addressed, since they depend substantially more on muscle strength, equilibrium and gait balance than on the mechanisms of oxygen and carbon dioxide transport to which interventions such as endurance training, bronchodilators and pulmonary vasoactive substances are directed. Other tests, such as the step test and the stair-climbing test, are mentioned only in the online supplementary material, since it was considered that there was insufficient published information at the time of writing to support their inclusion.

\section{Methods}

Studies that report the evaluation or use of the incremental (or ramp) exercise test (IET), the constant work-rate exercise test (CWRET), the 6-min walk test (6MWT), the incremental shuttle walk test (ISWT) and the endurance shuttle walk test (ESWT) in adults and children with chronic respiratory diseases were reviewed, without restrictions on study design. MEDLINE and the Cochrane Library were searched from 1990 to December 21, 2014. Selected references considered of great relevance were included up to March 2015. Reference lists of all primary studies and review articles were examined for additional citations. Only studies written in English, or for which an English translation was available, were consulted. Studies were included that referred (singly or in combination) to reported validity (i.e. the extent to which a test or variable is related to the function of a physiological system or to patient-meaningful variables such as symptoms or physical activity), precision or reproducibility, prognostic information (i.e. relationship with the natural history of the disease), discrimination (i.e. whether a variable can differentiate the severity of the disease as conventionally measured), clinical meaningful difference and test response to interventions. Reviewers excluded studies that did not meet the inclusion criteria based on title or abstract. Studies that met the inclusion criteria were retrieved in full text to determine whether they were suitable for inclusion. The articles included by the primary author of each section were approved by a second reviewer with expertise in the field. In case of discrepancies, differences were resolved by consensus.

\section{Laboratory-based exercise tests}

Laboratory-based tests are conducted on either a cycle ergometer or a motorised treadmill. Broad arrays of physiological responses are measured, most commonly on a breath-by-breath basis, throughout the test, at the limit of tolerance and in recovery $[3,4]$.

\section{Incremental work-rate tests}

The IET permits the evaluation of both submaximal and peak exercise responses, providing several indices relevant to the evaluation of patients with respiratory diseases $[3,4,16]$. This allows the identification of underlying mechanisms of exercise intolerance $[3,17,18]$. Use of the IET can also rule out certain medical conditions that pose a risk for exercise interventions, thus increasing their safety $[3,18]$. 
Procedure

As the procedure is well standardised and is automated (i.e. computer-driven cycle ergometer or treadmill), there is little interoperator variability $[3,18]$. The cycle ergometer has more advocates than the treadmill because it is less expensive, occupies little space, is less prone to movement artefacts so making it easier to take additional measurements, requires relatively little patient practice and (unlike the treadmill) the external power output is accurately known $[3,18]$. Conversely, walking on the treadmill may be more familiar to the patient $[3,18]$. Physiological responses to cycle ergometer and treadmill tests differ, as can the physiological mechanisms limiting exercise tolerance. For example, in COPD patients, cycle ergometry results in a greater likelihood of exercise intolerance resulting from leg fatigue than from dyspnoea [19] (online supplementary material). However, arterial desaturation occurs more frequently with treadmill walking than with cycling in COPD patients [20]. Imposing linear incremental work-rate (WR) profiles for treadmill exercise can be problematic, because most speed/grade increments incorporated into clinical exercise testing do not result in linear increases in WR [21]. A useful recent development is a protocol that generates a linear WR profile through continuous incrementing of both speed and grade [21]. Continuous monitoring of arterial oxygen saturation $\left(\mathrm{S}_{\mathrm{pO}_{2}}\right)$ and heart rate, with verbal encouragement during the test, are recommended [3] (table 1).

It is conventional practice in healthy individuals to select the rate at which WR is incremented $(\Delta \mathrm{WR} / \Delta \mathrm{t})$ for an IET such that the tolerable limit (tLIM) is reached within $\sim 10 \mathrm{~min}[3,18]$; i.e. $\Delta \mathrm{WR} / \Delta \mathrm{t}$ does not affect peak oxygen uptake ( $V^{\prime} \mathrm{O}_{2}$ peak) [22] (online supplementary material). However, no recommendations have been developed for respiratory disease populations. Some data suggest that shorter test durations (e.g. 5-9 $\mathrm{min}$ ) may be as suitable for COPD [23]. A $\Delta \mathrm{WR} / \Delta \mathrm{t}$ of $5-10 \mathrm{~W} \cdot \mathrm{min}^{-1}$ may be used in more severe patients to ensure a sufficient test duration $[3,18]$. However, as oxygen uptake lags WR throughout the IET, peak WR (WRpeak) will be higher the more rapidly WR is incremented [22] (online supplementary material).

Most modern breath-by-breath cardiopulmonary exercise testing systems provide a variety of possibilities regarding data averaging (suitably designed mixing chamber systems can provide adequate temporal resolution for incremental testing). Differences in data averaging (i.e. number of breaths, or time intervals such as 10, 20 or $30 \mathrm{~s}$ ) can have profound effects on some variables (table 1). Averaging of data over 2030-s intervals has been recommended [3], but 10-s averages have also been used in some trials [24-26]. Therefore, data averaging needs to be standardised and maintained constant within any given trial.

Safety

Adverse events are rare during properly supervised tests (table 1). In the largest study looking at 5060 cardiopulmonary exercise tests in high-risk cardiovascular patients, including 196 PAH patients, the adverse event rate was $0.16 \%$ with no fatalities [27]. In a study of PAH in adults, there were no events in 242 tests [28]. Cardiopulmonary exercise testing appears also to be safe in the paediatric population [29]. In patients without known cardiac problems, the complication rate is even lower, with a rate of death of 2-5 per 100000 tests [3]. Personnel conducting tests should be qualified to detect potentially life-threatening signals and follow safety recommendations $[3,18]$ (table 1 ).

Peak oxygen uptake

$V^{\prime} \mathrm{O}_{2}$ peak represents the highest oxygen uptake $\left(V^{\prime} \mathrm{O}_{2}\right)$ achieved in the IET at the subject's limit of tolerance; i.e. it is a symptom-limited measure. With good subject effort, $V^{\prime} \mathrm{O}_{2}$ peak is closely reflective of the subject's "maximum" $V^{\prime} \mathrm{O}_{2}$, the gold-standard index of aerobic capacity $[3,18]$.

Validity

$V^{\prime} \mathrm{O}_{2}$ peak is a useful outcome (tables 1 and 2) because normal reference values have been better established than for other exercise variables $[3,18]$ and because, combined with other response variables obtained in the IET, characteristic pathophysiological profiles of the underlying causes of impairment can be discerned $[3,18,30]$. Sufficient aerobic capacity is required to adequately perform daily living activities [31] and $V^{\prime} \mathrm{O}_{2}$ peak demonstrates a good correlation $(\mathrm{r}=0.54)$ with daily living activity [32].

With appropriate quality control measures (i.e. verification of calibration gases, training of personnel from the different laboratories on the procedures, and serial biological controls), $V^{\prime} \mathrm{O}_{2}$ peak is consistent among different laboratories in multisite COPD clinical trials [24, 33]. Inaccurate results from less-experienced sites [34] was considered the cause of the failure of $V^{\prime} \mathrm{O}_{2}$ peak to show an effect with the approved dose $(100 \mathrm{mg})$ of sitaxsentan (an endothelin-A receptor antagonist) in the Strategies to Increase Confidence, Independence and Energy (STRIDE)-1 study [35]. Therefore, to use $V^{\prime} \mathrm{O}_{2}$ peak as an outcome in clinical trials, quality control measures should be taken, peak criteria standardised and expertise validated at all sites. 
TABLE 1 Characteristics of the tests reviewed

$\begin{array}{cccccc}\begin{array}{c}\text { Main } \\ \text { variables }\end{array} & \begin{array}{c}\text { Physiological/ } \\ \text { perceptual } \\ \text { variables }\end{array} & \begin{array}{c}\text { Reference } \\ \text { values }\end{array} & \text { Safety } & \text { Facilities } & \begin{array}{c}\text { Multicentre } \\ \text { Prognostic } \\ \text { trials } \\ \text { experience }\end{array}\end{array}$

\begin{tabular}{|c|c|c|c|c|c|c|c|c|}
\hline IET & $\begin{array}{l}V^{\prime} \mathrm{O}_{2} \text { peak, } \\
\text { WRpeak, } \theta \mathrm{L} \\
\text { and } V^{\prime} \mathrm{E}-V^{\prime} \mathrm{CO}_{2} \\
\text { indices }\end{array}$ & $\begin{array}{c}V^{\prime} \mathrm{O}_{2}, V^{\prime} \mathrm{E}, \mathrm{WR}, \\
\mathrm{HR}, \theta \mathrm{L}, V^{\prime} \mathrm{E}-V^{\prime} \mathrm{CO}_{2} \\
\text { indices, } \mathrm{SpO}_{2} \text {, } \\
\text { dyspnoea, } \\
\text { leg fatigue, IC, } \\
\text { flow-volume } \\
\text { and blood } \\
\text { analysis }\end{array}$ & $\begin{array}{l}\text { Available for } \\
V^{\prime} \mathrm{O}_{2} \text { peak, } \\
\text { WRpeak, } \\
\mathrm{HR} \text { peak and } \\
V^{\prime} \mathrm{E}-V^{\prime} \mathrm{CO}_{2} \\
\text { indices }\end{array}$ & $\begin{array}{l}\text { 2-5/100000 severe } \\
\text { accidents; } \\
\text { monitoring and } \\
\text { CPR available or at } \\
\text { hand } \\
\text { recommended }\end{array}$ & $\begin{array}{l}\text { Cycle or } \\
\text { treadmill, a } \\
\text { room, metabolic } \\
\text { system, cardiac } \\
\text { monitoring and } \\
\text { pulse oximeter }\end{array}$ & +++ & Survival & $\begin{array}{c}\text { Relatively expensive; } \\
\text { additional } \\
\text { measurements } \\
\text { easier on cycle }\end{array}$ \\
\hline CWRET & $\begin{array}{l}\text { tLIM, isotime } \\
\qquad I C \text { and } \\
\text { perceptions }\end{array}$ & $\begin{array}{c}\text { Isotime } \mathrm{V}^{\prime} \mathrm{O}_{2}, V^{\prime} \mathrm{E}, \\
\mathrm{WR}, \mathrm{HR}, \mathrm{SpO}_{2} \text {, } \\
\text { dyspnoea, } \\
\text { leg fatigue, } \\
\text { flow-volume } \\
\text { and blood } \\
\text { analysis, IC and } \\
\text { others }\end{array}$ & & $\begin{array}{c}\text { Good; monitoring } \\
\text { and CPR available } \\
\text { or at hand } \\
\text { recommended } \#\end{array}$ & $\begin{array}{c}\text { Cycle or } \\
\text { treadmill, a } \\
\text { room, metabolic } \\
\text { system or } \\
\text { spirometer, } \\
\text { cardiac } \\
\text { monitoring and } \\
\text { pulse oximeter }\end{array}$ & +++ & & $\begin{array}{c}\text { Relatively expensive; } \\
\text { can be performed } \\
\text { without metabolic } \\
\text { system; additional } \\
\text { measurements } \\
\text { easier on cycle }\end{array}$ \\
\hline ISWT & $\begin{array}{c}\text { Distance and } \\
\text { dyspnoea }\end{array}$ & $\begin{array}{c}\mathrm{HR}, \mathrm{SpO}_{2}, \\
\text { dyspnoea and } \\
\text { leg fatigue }\end{array}$ & Available & $\begin{array}{l}\text { Not measured; } \\
\text { monitoring and } \\
\text { CPR available or at } \\
\text { hand } \\
\text { recommended }^{\#}\end{array}$ & $\begin{array}{c}\text { 10-m corridor } \\
\text { and pulse } \\
\text { oximeter }\end{array}$ & ++ & $\begin{array}{l}\text { Survival } \\
\text { re-admission } \\
\text { (in COPD) }\end{array}$ & $\begin{array}{l}\text { Audio signal under } \\
\text { copyright; walk tests } \\
\text { induce more } \\
\text { desaturation }\end{array}$ \\
\hline ESWT & $\begin{array}{l}\text { Time or } \\
\text { distance, } \\
\text { dyspnoea }\end{array}$ & $\begin{array}{c}\mathrm{HR}, \mathrm{SpO}_{2} \text {, } \\
\text { dyspnoea, leg } \\
\text { fatigue }^{\pi}\end{array}$ & & $\begin{array}{c}\text { Good; monitoring } \\
\text { and CPR available } \\
\text { or at hand } \\
\text { recommended }\end{array}$ & $\begin{array}{c}\text { 10-m corridor } \\
\text { and pulse } \\
\text { oximeter }\end{array}$ & ++ & & $\begin{array}{l}\text { Audio signal under } \\
\text { copyright; walking } \\
\text { tests induce more } \\
\text { desaturation }\end{array}$ \\
\hline 6MWT & $\begin{array}{c}\text { Distance and } \\
\text { dyspnoea }\end{array}$ & $\begin{array}{c}\mathrm{HR}, \mathrm{SpO}_{2} \text {, } \\
\text { dyspnoea and } \\
\text { leg fatigue }\end{array}$ & Available & $\begin{array}{l}\text { Good; not as much } \\
\text { experience as with } \\
\text { laboratory tests; } \\
\text { monitoring and } \\
\text { CPR available or } \\
\text { at hand } \\
\text { recommended }^{\#}\end{array}$ & $\begin{array}{c}\text { 30-m corridor } \\
\text { and pulse } \\
\text { oximeter }\end{array}$ & +++ & $\begin{array}{c}\text { Survival; } \\
\text { hospitalisation } \\
\text { and } \\
\text { exacerbations (in } \\
\text { COPD) }\end{array}$ & $\begin{array}{c}\text { Dependent on } \\
\text { encouragement and } \\
\text { track length and } \\
\text { layout; walk tests } \\
\text { induce more } \\
\text { desaturation }\end{array}$ \\
\hline
\end{tabular}

IET: incremental exercise test; CWRET: constant work-rate exercise test; ISWT: incremental shuttle walk test; ESWT: endurance shuttle walk test; 6MWT: 6-min walk test; $V^{\prime} \mathrm{O}_{2}$ peak: peak oxygen uptake; WRpeak: peak work-rate (or peak power); $\theta$ L: lactate threshold; $V^{\prime} \mathrm{E}-V^{\prime} \mathrm{CO}_{2}:$ ventilation- $\mathrm{CO}_{2}$ output indices; $V^{\prime} \mathrm{O}_{2}$ : oxygen uptake; $V^{\prime} \mathrm{E}$ : minute ventilation; WR: work-rate; HR: heart rate; $\mathrm{SpO}_{2}$ : arterial oxygen saturation measured by pulse oximetry; IC: inspiratory capacity; HRpeak: peak heart rate; CPR: cardiopulmonary resuscitation; tLIM: time to the limit of tolerance, typically for constant work-rate tests; COPD: chronic obstructive pulmonary disease. " : CWRT and ESWT are usually performed after an IET or a ISWT, respectively, in which the safety of exercising is assessed; " : additional physiological information if a portable (expensive) metabolic system is used.

\section{Precision}

$V^{\prime} \mathrm{O}_{2}$ peak is remarkably repeatable, with no learning effect and coefficients of variation ranging from $3 \%$ to $9 \%$ in respiratory patients $[3,28,36]$ (tables 1 and 2 ). Therefore, there is no need to perform more than one baseline IET in clinical trials when maximal effort criteria are standardised.

\section{Prognostic information}

$V^{\prime} \mathrm{O}_{2}$ peak is an excellent general predictor of survival for most chronic respiratory diseases $[5,6,9-12,37,38]$. In one study, $V^{\prime} \mathrm{O}_{2}$ peak (but not 6-min walking distance (6MWD)) was able to predict clinical stability in idiopathic PAH [39]. However, to date there is little information on the impact on survival of interventions yielding improvements in $V^{\prime} \mathrm{O}_{2}$ peak in respiratory patients.

\section{Discrimination}

$V^{\prime} \mathrm{O}_{2}$ peak can gauge severity in PAH patients [40]. In COPD, $V^{\prime} \mathrm{O}_{2}$ peak can stratify severity by survival [5] and spirometric Global Initiative for Chronic Obstructive Lung Disease (GOLD) stages [41]. In interstitial pulmonary fibrosis (IPF), arterial oxygen tension at $V^{\prime} \mathrm{O}_{2}$ peak can also help to gauge severity [2]. 
TABLE 2 Measurement properties of the tests reviewed

\begin{tabular}{|c|c|c|c|c|c|}
\hline & Main variables & $\begin{array}{l}\text { Practice test } \\
\text { needed }\end{array}$ & Standardisation & MCID & Reproducibility \\
\hline IET & $\begin{array}{c}V^{\prime} \mathrm{O}_{2} \text { peak, WRpeak and } \\
V^{\prime} \mathrm{E}-V^{\prime} \mathrm{CO}_{2} \text { indices }\end{array}$ & No & $\begin{array}{l}\text { Adjusting WR increments } \\
\text { to the patient capacity } \\
\text { Criteria for "good effort" }\end{array}$ & $\begin{array}{c}\text { No } \\
\text { Suggested targets in PAH: } \\
V^{\prime} \mathrm{O}_{2}>10 \mathrm{~L} \cdot \mathrm{min}^{-1} \cdot \mathrm{kg}^{-1} \\
V^{\prime} \mathrm{E}-V^{\prime} \mathrm{CO}_{2} \text { slope }<45\end{array}$ & $\begin{array}{c}V^{\prime} \mathrm{O}_{2} \text { peak } 5-10 \% \\
\text { WRpeak } 5-10 \% \\
V^{\prime} \mathrm{E}-V^{\prime} \mathrm{CO}_{2} \text { indices } \pm 2.3 \\
\text { both within and } \\
\text { between individuals }\end{array}$ \\
\hline ISWT & $\begin{array}{l}\text { Time/distance, } \\
\text { dysponea and } \mathrm{SpO}_{2}\end{array}$ & Yes & Audio signal & $47 \mathrm{~m}$ & NA \\
\hline 6MWT & $\begin{array}{c}\text { Distance } / \mathrm{SpO}_{2} \text { and } \\
\text { dyspnoea }\end{array}$ & Yes & $\begin{array}{l}\text { Track length } \\
\text { Encouragement }\end{array}$ & $\begin{array}{c}25-33 \mathrm{~m} \\
\text { In PAH, MCID relates to symptom } \\
\text { amelioration, } \\
\text { but not to survival }\end{array}$ & $\begin{array}{l}\text { Distance } 5-8 \% \text { when } \\
\text { performed twice } \\
\text { within individuals }\end{array}$ \\
\hline
\end{tabular}

MCID: minimal clinically important difference; IET: incremental exercise test; CWRET: constant work-rate exercise test; ISWT: incremental shuttle walk test; ESWT: endurance shuttle walk test; $6 \mathrm{MWT}$ : standardised 6-min walk test; $V^{\prime}{ }_{2}$ peak: peak oxygen uptake; WRpeak: peak work-rate (or peak power); $V^{\prime} \mathrm{E}-V^{\prime} \mathrm{CO}_{2}$ : ventilation-carbon dioxide output indices; WR: work-rate; PAH: pulmonary arterial hypertension; $V^{\prime} \mathrm{O}_{2}$ : oxygen uptake; tLIM: tme to the limit of tolerance, typically for constant work-rate tests; IC: inspiratory capacity; $\mathrm{SpO}_{2}$ : arterial blood oxygen saturation measured by pulse oximetry; NA: not applicable.

\section{Clinically meaningful difference}

There is very little information about what constitutes a minimal clinically important difference (MCID) in $V^{\prime} \mathrm{O}_{2}$ peak (table 2). In the National Emphysema Treatment Trial (NETT), $4 \pm 1 \mathrm{~W}$ was considered the symptoms-anchored MCID for severe COPD patients [42], translating into a $V^{\prime} \mathrm{O}_{2}$ peak change of $\sim 0.04 \pm 0.01 \mathrm{~L} \cdot \mathrm{min}^{-1}$.

In patients with $\mathrm{PAH}, V^{\prime} \mathrm{O}_{2}$ peak has been suggested as a goal of therapy, with $<10 \mathrm{~mL} \cdot \mathrm{min}^{-1} \cdot \mathrm{kg}^{-1}$ indicating poor prognosis and the need to escalate treatment and $>15 \mathrm{~mL} \cdot \mathrm{min}^{-1} \cdot \mathrm{kg}^{-1}$ indicating better prognosis [43].

\section{Evaluative aspects}

Regarding nonpharmacological interventions, several studies including GOLD stages 2-4 COPD patients of widely ranging age (some aged $>75$ years) [44] have shown significant, yet modest, increases in $V^{\prime} \mathrm{O}_{2}$ peak after lower-limb endurance muscle training [25, 44-47]. In general, endurance training increases $V^{\prime} \mathrm{O}_{2}$ peak in PAH [48, 49] IPF [50], cystic fibrosis [51, 52] and asthma [53]. Reported changes following pulmonary rehabilitation in COPD patients are in the range $0.1-0.5 \mathrm{~L} \cdot \mathrm{min}^{-1}$ or $\sim 10-40 \%$ of baseline, with a mean improvement of $\sim 11 \%$ [54]. Rehabilitation in PAH patients increases $V^{\prime} \mathrm{O}_{2}$ peak by $1-1.5 \mathrm{~mL} \cdot \mathrm{min}^{-1} \cdot \mathrm{kg}^{-1}$ $[48,49]$, and a similar responsiveness is observed in IPF patients [50]. Lung transplant surgery $[55,56]$ and successful lung volume reduction surgery [57] also consistently result in a greater post-intervention $V^{\prime} \mathrm{O}_{2}$ peak (table 3). $V^{\prime} \mathrm{O}_{2}$ peak has been also shown to be responsive to oxygen therapy both in patients with COPD and those with cystic fibrosis who desaturate during exercise $[58,59]$.

With regard to pharmacological interventions, $V^{\prime} \mathrm{O}_{2}$ peak can improve after short- [60] and long-acting inhaled bronchodilator therapy [60-63] in COPD patients, although the magnitude of this response tends to be modest $\left(0.04-0.18 \mathrm{~L} \cdot \mathrm{min}^{-1}\right)$ [60] and it is not always evident $[60,64] . V^{\prime} \mathrm{O}_{2}$ peak has been able to detect the long-term (i.e. 3-12 months) effects of several approved pharmacological therapies for PAH. The effects seen in idiopathic PAH are of the order of $1.5-2 \mathrm{~mL} \cdot \mathrm{min}^{-1} \cdot \mathrm{kg}^{-1}$ or $\sim 9-14 \%[65,66]$. In one PAH study, the effect observed was less deterioration than in the control group $(-7 \%$ versus $-16 \%$, respectively) [67]; however, this is not the case in all studies [35]. $V^{\prime} \mathrm{O}_{2}$ peak has been shown to significantly improve after oxygen therapy in IPF [68] and COPD [69]. 
TABLE 3 Responsiveness of the tests to rehabilitation

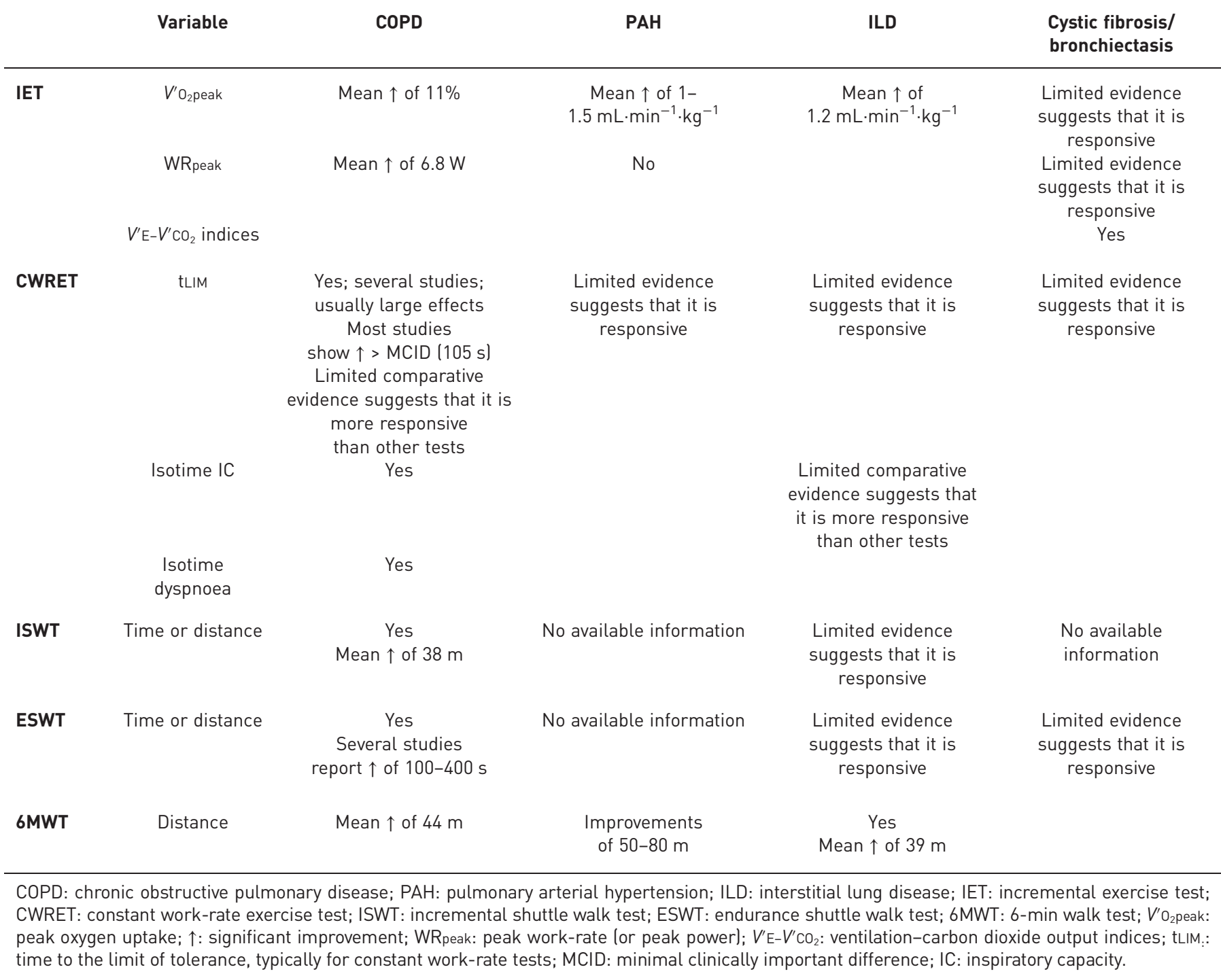

Peak work-rate

WRpeak is the highest WR achieved in an IET at the subject's limit of tolerance. It has the advantage over $V^{\prime} \mathrm{O}_{2}$ peak that it can be determined without a metabolic measurement system. However, a disadvantage is that it is dependent on the rate of WR increase [22] (online supplementary material).

\section{Precision}

Coefficients of variation for WRpeak in adult respiratory patients range from 3.5\% to $13.8 \%$, averaging $7.5 \%$ [3]. In children with cystic fibrosis, WRpeak appears to be slightly less reproducible, with a coefficient of variation $\sim 10 \%$ [70] (table 2).

\section{Prognostic information}

There is little direct information about the predictiveness of WRpeak, since most of the studies evaluating the IET have focused on $V^{\prime} \mathrm{O}_{2}$ peak. WRpeak in children with cystic fibrosis [71] and in adults with PAH is predictive of survival [12] (table 1).

\section{Discrimination}

WRpeak differs among COPD patients according to spirometric GOLD stage, but with significant overlap [41]. 


\section{Clinically meaningful difference}

From the NETT data, anchor- and distribution-based analysis suggested $4 \pm 1 \mathrm{~W}$ as the MCID for severe COPD patients [42] (table 2).

\section{Evaluative aspects}

WRpeak is at least as responsive as $V^{\prime} \mathrm{O}_{2}$ peak to rehabilitative interventions in studies including COPD patients ranging widely in age and severity $[25,44-47,72]$. In a meta-analysis of 16 studies of pulmonary rehabilitation, the mean (95\% CI) pooled effect was 6.8 (1.9-11.6) W increase in WRpeak [73]. Another systematic review comparing continuous with interval training reported increases (95\% CI) in WRpeak of $11(9-13) \mathrm{W}$ and $10(8-11) \mathrm{W}$, respectively [74]. WRpeak increases after rehabilitation in PAH patients by 15-25 W [48, 49] (table 3). WRpeak was also increased after lung volume reduction surgery [42, 57]. Oxygen therapy has shown average increases of $\geqslant 10 \mathrm{~W}$ in patients with COPD, IPF and cystic fibrosis who desaturate during exercise $[58,59,75]$.

WRpeak was an outcome in a few studies with both short-acting (salbutamol and ipratropium) and long-acting (formoterol, salmeterol and tiotropium) bronchodilators in COPD patients. Most, but not all of these studies reported significant, yet small (i.e. 3-10 W) improvements in WRpeak [60, 64] (table 4).

\section{Ventilation-carbon dioxide output indices}

Procedure

There is some controversy in the literature about how best to estimate the slope of the ventilation-carbon dioxide output $\left(V^{\prime} \mathrm{E}-V^{\prime} \mathrm{CO}_{2}\right)$ relationship (online supplemenary material). We recommend that the slope estimation is confined to the demonstrably linear region of the $V^{\prime} \mathrm{E}-V^{\prime} \mathrm{CO}_{2}$ relationship, i.e. excluding the curvilinear region beyond the point at which arterial $\left(\mathrm{PaCO}_{2}\right)$ and end-tidal carbon dioxide tension are reduced by ventilatory compensation for the exercise-associated metabolic acidosis. Because $V^{\prime} \mathrm{E}-V^{\prime} \mathrm{CO}_{2}$ minimum (i.e. the lowest value attained on the IET, typically at the respiratory compensation point) and $V^{\prime} \mathrm{E}-V^{\prime} \mathrm{CO}_{2}$ at the lactate threshold $(\theta \mathrm{L})$ (online supplemenary material) are so similar $(\mathrm{r}=0.99$; with limits of agreement $\sim \pm 1$ ) and $\theta \mathrm{L}$ may be difficult to discern in some respiratory patients, $V^{\prime} \mathrm{E}-V^{\prime} \mathrm{CO}_{2}$ minimum may be a more reliable measurement to use [76].

\section{Validity}

Both $V^{\prime} \mathrm{E}-V^{\prime} \mathrm{CO}_{2}$ slope and $V^{\prime} \mathrm{E}-V^{\prime} \mathrm{CO}_{2}$ minimum are typically elevated in most respiratory and cardiac diseases, reflective of an increased dead space and/or decreased $\mathrm{PaCO}_{2}$ set-point $[3,40,43,65,66]$ (online supplemenary material). In $\mathrm{PAH}$ patients, $V^{\prime} \mathrm{E}-V^{\prime} \mathrm{CO}_{2}$ indices or their changes with interventions correlate

TABLE 4 Responsiveness of the different tests to bronchodilators for chronic obstructive pulmonary disease (COPD), vasodilators for pulmonary arterial hypertension (PAH) or pirfenidone for idiopathic pulmonary fibrosis (IPF)

\begin{tabular}{|c|c|c|c|c|}
\hline IET & $\begin{array}{c}V^{\prime} \mathrm{O}_{2} \text { peak } \\
V^{\prime} \mathrm{E}-V^{\prime} \mathrm{CO}_{2} \text { indices }\end{array}$ & $\begin{array}{c}\text { Modest and inconsistent } \uparrow \text {; few studies } \\
\text { Anecdotal evidence }\end{array}$ & $\begin{array}{c}1.5-2 \mathrm{~mL} \cdot \mathrm{min}^{-1} \cdot \mathrm{kg}^{-1} \text { or } \\
\uparrow 9-14 \% \\
\uparrow 3-6 \text { units } / 10-30 \%\end{array}$ & \\
\hline CWRET & $\begin{array}{c}\text { tLIM } \\
\text { Isotime IC and dyspnoea }\end{array}$ & $\begin{array}{l}14 / 26(54 \%) \text { and } 3 / 11(27 \%) \text { of reviewed } \\
\text { studies on long- and short-acting bronchodilators, } \\
\text { respectively, showed } \uparrow>M C I D(105 \mathrm{~s}) \\
\text { Limited comparative evidence suggest that it is } \\
\text { more responsive than other tests } \\
\text { Most studies show } \uparrow>0.2 \mathrm{~L} \text { and are associated } \\
\text { with improvements in dyspnoea } \\
\text { intensity of } \geqslant 1 \text { unit on a Borg scale }\end{array}$ & & \\
\hline ISWT & Time/distance & Inconsistent $\uparrow$; few studies & & \\
\hline
\end{tabular}


significantly with pulmonary artery pressure and with increased pulmonary vascular resistance (PVR) or changes in PVR [65, 77, 78], and their profiles can detect right-to-left shunt (e.g. foramen ovale) [79]. In $\mathrm{COPD}, V^{\prime} \mathrm{E}-V^{\prime} \mathrm{CO}_{2}$ slope correlates with the degree of emphysema $(\mathrm{r}=0.77)$ as measured by computed tomography [80]. Reference values for $V^{\prime} \mathrm{E}-V^{\prime} \mathrm{CO}_{2}$ minimum have been established [76].

\section{Precision}

Test-retest reproducibility is similar for $V^{\prime} \mathrm{E}-V^{\prime} \mathrm{CO}_{2}$ slope and $V^{\prime} \mathrm{E}-V^{\prime} \mathrm{CO}_{2}$ minimum in healthy adults (i.e. 95\% CI \pm 2.3 ) [81], although better reproducibility has been reported for $V^{\prime} \mathrm{E}-V^{\prime} \mathrm{CO}_{2}$ minimum and $V^{\prime} \mathrm{E}-V^{\prime} \mathrm{CO}_{2}$ at $\theta \mathrm{L}$ than for $V^{\prime} \mathrm{E}-V^{\prime} \mathrm{CO}_{2}$ slope [76]. $V^{\prime} \mathrm{E}-V^{\prime} \mathrm{CO}_{2}$ slope is repeatable in $\mathrm{PAH}$ and cardiac patients (coefficient of variation $\sim 5 \%$, range $1-11 \%$ ) $[28,82]$ (table 2).

\section{Prognostic information}

$V^{\prime} \mathrm{E}-V^{\prime} \mathrm{CO}_{2}$ slope is predictive of survival in idiopathic PAH [77, 83], cystic fibrosis [71] and IPF [37]. However, changes in $V^{\prime} \mathrm{E}-V^{\prime} \mathrm{CO}_{2}$ indices after interventions are not as predictive of survival and clinical events as $V^{\prime} \mathrm{O}_{2}$ peak in idiopathic PAH $[39,77]$ (table 1).

\section{Discrimination}

$V^{\prime} \mathrm{E}-V^{\prime} \mathrm{CO}_{2}$ indices can detect patients with $\mathrm{PAH}$ and left-to-right shunt [79]. $V^{\prime} \mathrm{E}-V^{\prime} \mathrm{CO}_{2}$ at $\theta \mathrm{L}$ increases in proportion to disease severity in PAH patients $[40,84]$. In a small sample of moderate and severe COPD patients, $V^{\prime} \mathrm{E}-V^{\prime} \mathrm{CO}_{2}$ at $\theta \mathrm{L}$ discriminated those with $\mathrm{PAH}$ from those without [85]. A high $V^{\prime} \mathrm{E}-V^{\prime} \mathrm{CO}_{2}$ slope also identified PAH in patients with IPF [86].

\section{Clinically meaningful difference}

No MCID has been established for any of the $V^{\prime} \mathrm{E}-V^{\prime} \mathrm{CO}_{2}$ indices. In $\mathrm{PAH}$, values for $V^{\prime} \mathrm{E}-V^{\prime} \mathrm{CO}_{2}$ at $\theta \mathrm{L}<45$ have been proposed as a target for treatment [43].

\section{Evaluation}

$V^{\prime} \mathrm{E}-V^{\prime} \mathrm{CO}_{2}$ slope did not change significantly after exercise training in PAH patients in two studies [48, 49] (table 3). $V^{\prime} \mathrm{E}-V^{\prime} \mathrm{CO}_{2}$ slope was reduced significantly after surgical (thromboendarterectomy and lung transplant) intervention and the decreases were strongly related to the reduction in PVR post-surgery [87, 88]. $V^{\prime} \mathrm{E}-V^{\prime} \mathrm{CO}_{2}$ indices respond to pharmacological interventions: with phosphodiesterase-5 inhibitors [89], endothelin receptor antagonists [67] and prostanoids [90-92] in idiopathic PAH; with bosentan and sildenafil in adult patients with Eisenmenger syndrome [93]; and with beraprost in patients with thromboembolic pulmonary hypertension [94]. Responses were generally between 3 and 6 units or 10-20\%. However, there was no effect of nitric oxide inhalation [95]. A study of ghrelin in underweight COPD patients showed an average reduction in $V^{\prime} \mathrm{E}-V^{\prime} \mathrm{CO}_{2}$ slope of $\sim 4$ units [96]. In cystic fibrosis, oxygen therapy reduced the minimum $V^{\prime} \mathrm{E}-V^{\prime} \mathrm{CO}_{2}[58]$.

\section{High-intensity constant work-rate exercise tests}

These tests are widely used to assess changes in exercise tolerance following interventions and the associated responses of key physiological and perceptual variables. The high-intensity CWRET has grown in popularity, particularly in COPD, because it can characterise exercise tolerance in a single exercise bout.

\section{Procedure}

As for the IET, CWRETs are typically performed on the treadmill $[25,97]$ or cycle ergometer $[26,62,98-104]$, although alternative modes of exercise better suited to the patient's limitations can be used. As for the IET, CWRET implementation is automated and it is therefore less operator-dependent if the criteria for test termination are standardised (table 1). An IET must first be completed (ideally on a separate day or at least allowing a sufficient rest period) for an appropriate WR for the CWRET to be estimated [105]. The most straightforward approach is to assign this WR based on a fixed percentage of IET WRpeak, although this approach has some limitations [106, 107] (online supplementary material).

Continuous monitoring of $\mathrm{SpO}_{2}$ and ECG, with verbal encouragement throughout, are recommended [3]. Concomitant gas exchange measurement increases the value of the test by providing insight into putative mediators of the exercise limitation. With cycle ergometer tests, it is important to define a priori the criteria to determine intolerance, e.g. the maximum duration for which the patient may pedal below a minimum pedalling frequency despite encouragement. Typical criteria for termination include $\leqslant 10 \mathrm{~s}$ sustained below a lower-bound target frequency despite verbal encouragement (typically $60 \mathrm{rpm}$, but bounds of 50-70 rpm for COPD patients are acceptable). The point at which the patient is unable to regain the target frequency despite encouragement defines tLIM.

We recommend limiting the target duration for the pre-intervention CWRET to between $180 \mathrm{~s}$ and $480 \mathrm{~s}$. There are some important physiological, statistical and practical reasons necessitating this relatively narrow range $[26,102,105,107]$ (online supplementary material). Exercise durations within this range are typically limited by the integrated functioning of cardiopulmonary and neuromuscular systems, rather than boredom or 
discomfort $[3,4,18]$. Physiologically, the relationship between WR and tLIM is not linear; therefore interpreting the magnitude of intervention-related tLIM change should be better made from a common baseline duration. Statistically, the variability of pre-intervention tLIM among subjects in published randomised controlled trials is typically high (coefficient of variation 20-60\%, median 42\%) (figures 1-3). The minimisation of interindividual

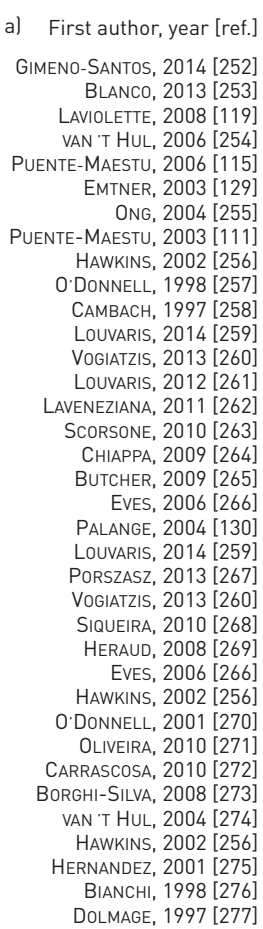

b) First author, year [ref.] GiMENO-SANTOS, 2014 [252] BLANCO, 2013 [253]

LAVIOLETTE, 2008 [119] VAN 'T HUL, 2006 [254] Puente-MAESTU, 2006 [115] EMTNER, 2003 [129]
ONG, 2004 [255] Puente-MAestu, 2003 [111]

HAWKINS, 2002 [256]

O.DONNELL, 1998 [257]

CAMBACH, 1997 [258]

LOUVARIS, 2014 [259]

VogIATZIS, 2013 [260]

LOUVARIS, 2012 [261]

LAVENEZIANA, 2011 [262]

CHIAPPA, 2009 [264]

BUTCHER, 2009 [265]

Eves, 2006 [266]

PALANGE, 2004 [130]

LOUVARIS, 2014 [259]

PORSZASZ, 2013 [267]

VogIATZIS, 2013 [260]

HERAUD, 2008 [269]

EVES, 2006 [266]

HAWKINS, 2002 [256]

O'DONNELL, 2001 [270]

OLIVEIRA, 2010 [271]

CARRASCOSA, 2010 [272]

BORGHI-SILVA, 2008 [273]

VAN 'T HUL, 2004 [274]

HAWKINS, 2002 [256]

HERNANDEZ, 2001 [275]

BIANCHI, 1998 [276]

DoLMAGE, 1997 [277]

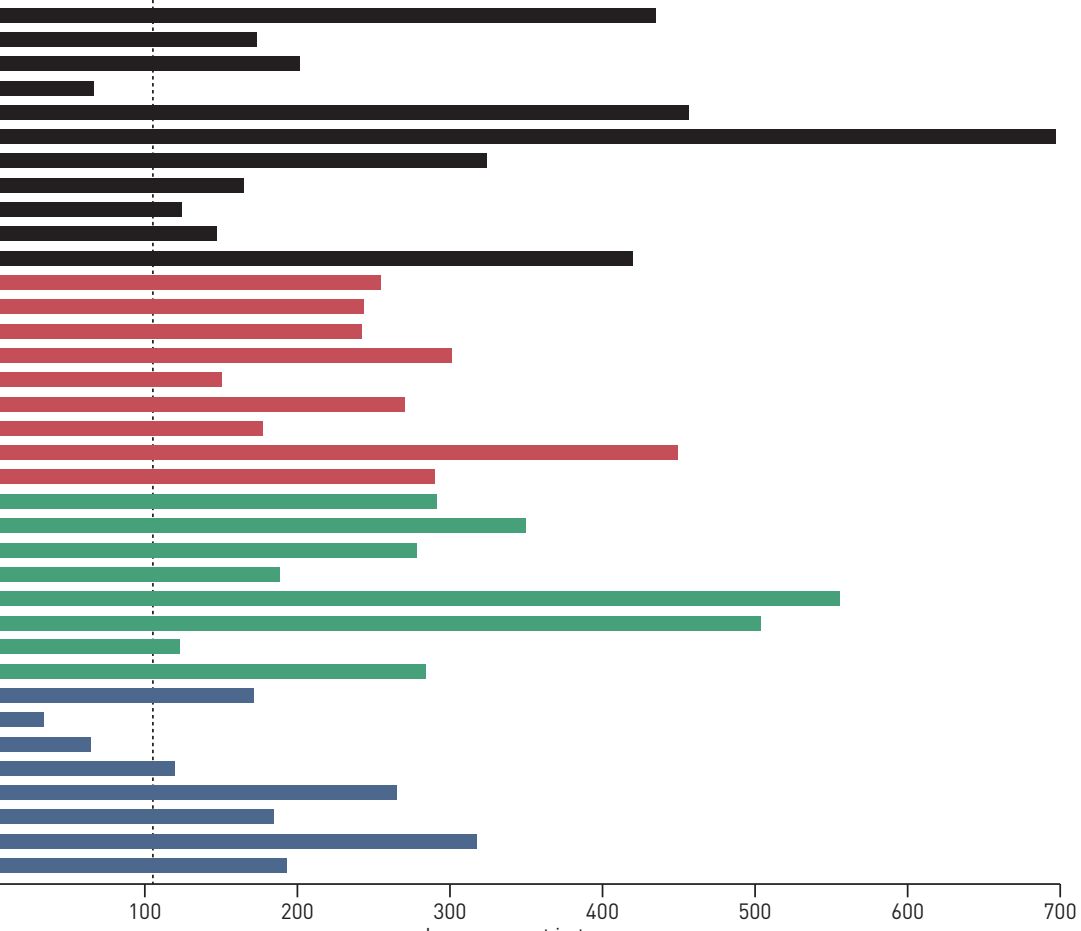

Subjects $\mathrm{n}$ FEV 1 L WR W

$\begin{array}{ccc}73 & 39 & 80 \\ 10 & 32 & 70 \\ 168 & 45 & 80 \\ 29 & 40 & 75 \\ 28 & 43 & 70 \\ 24 & 36 & 75 \\ 37 & 42 & 80 \\ 21 & 40 & 70 \\ 19 & 27 & 70 \\ 20 & 41 & 75 \\ 130 & 59 & 75 \\ 10 & 46 & 75 \\ 12 & 42 & 75 \\ 17 & 47 & 75 \\ 11 & 40 & 80 \\ 30 & 50 & 80 \\ 12 & 45 & 75 \\ 11 & 52 & 80 \\ 10 & 47 & 60 \\ 12 & 38 & 80 \\ 10 & 46 & 75 \\ 15 & 32 & 80 \\ 12 & 42 & 75 \\ 11 & 47 & 75 \\ 25 & 52 & 60 \\ 10 & 47 & 60 \\ 19 & 27 & 70 \\ 105 & 37 & 75 \\ 21 & 40 & 75 \\ 20 & 39 & 75 \\ 16 & 42 & 75 \\ 45 & 39 & 75 \\ 19 & 27 & 70 \\ 8 & 26 & 80 \\ 15 & 32 & 80 \\ 10 & 29 & 65 \\ & & \end{array}$

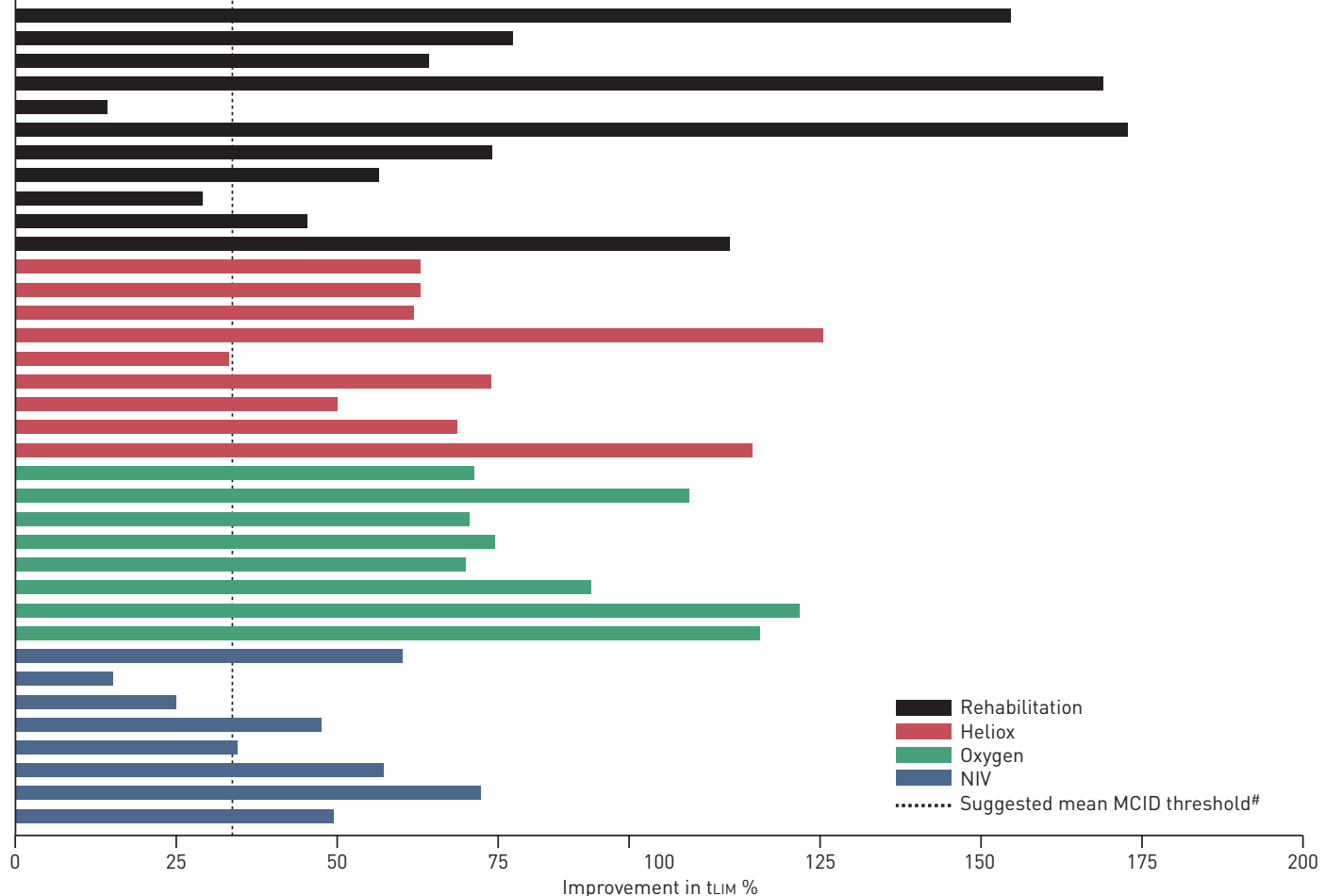

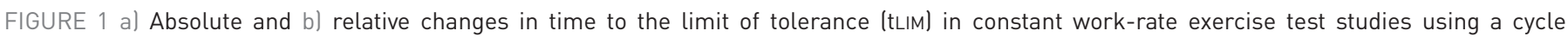
ergometer with nonpharmacological interventions in chronic obstructive pulmonary disease patients. FEV1: forced expiratory volume in 1 s; WR: work-rate; NIV: noninvasive ventilation; MCID: minimum clinically important difference. ${ }^{\#}$ : suggested mean MCID thresholds a) 105 s (lower limit of $95 \% \mathrm{Cl} 60$ s); b) $33 \%$ (lower limit of $95 \% \mathrm{Cl} 22 \%$ ) [102]. 
a) First author, year [ref.]

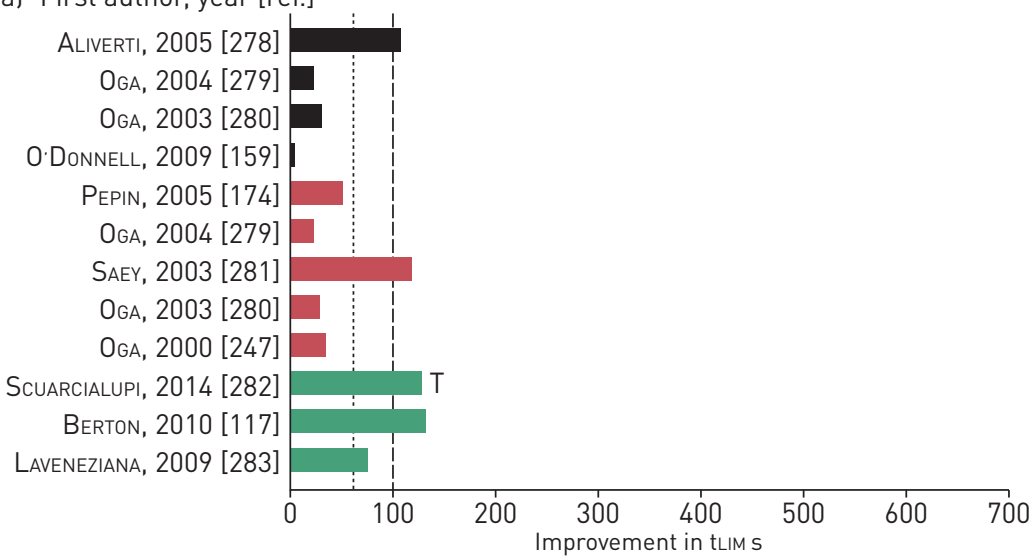

Subjects n FEV 1 L WR W

$\begin{array}{lll}37 & 47 \quad 80\end{array}$

67
16

$16 \quad 90 \quad 85$

$17 \quad 56 \quad 80$

$\begin{array}{lll}37 & 47 \quad 80\end{array}$

$18 \quad 38 \quad 80$

$67 \quad 44 \quad 80$

$38 \quad 41 \quad 80$

$30 \quad 46 \quad 75$

$12 \quad 38 \quad 75$

$12 \quad 57 \quad 75$

b) First author, year [ref.]

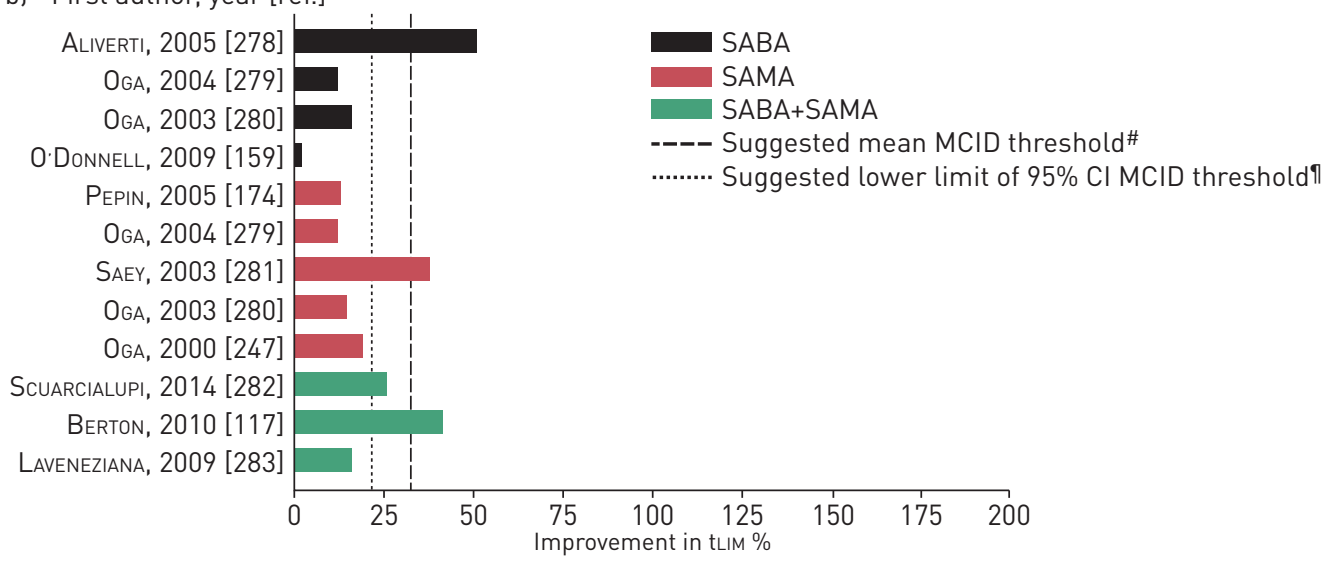

FIGURE 2 a) Absolute and b) percentage changes in time to the limit of tolerance (tLIM) in constant work-rate exercise test studies using a cycle ergometer in relation to placebo with short-acting $\beta_{2}$-adrenoceptor agonists (SABA), short-acting antimuscarinics (SAMA) and their combination in chronic obstructive pulmonary disease patients. Descriptive data for individual studies are shown only once. FEV1: forced expiratory volume in $1 \mathrm{~s}$; WR: work-rate; MCID: minimum clinically important difference. \#: suggested mean MCID thresholds a) $105 \mathrm{~s}$, b) $33 \%$; ๆ: suggested lower limit of $95 \% \mathrm{CI}$ MCID thresholds a) $60 \mathrm{~s}, \mathrm{~b}) 22 \%$ [102].

variability $[105,107]$ can therefore economise the sample size needed to detect an effect. Practically, long exercise tests are undesirable for both the patient and the testing facility. Furthermore, elimination of long baseline tLIM values will reduce the occurrence of very long post-intervention tests (most frequently seen after muscle training), requiring premature termination by the investigators and therefore invalidating interpretation of the magnitude of intervention-related tLIM change using parametric statistics [26, 105, 107].

Typically, CWRET WRs are selected to be $75-80 \%$ of IET WRpeak. Pooled data from one retrospective [108] and two prospective [33, 109] studies (total $n=2608$ ) suggest that $75-80 \%$ WRpeak results in the target tLIM being achieved in $\sim 57 \%$ of COPD patients ( $25 \%<180 \mathrm{~s}$ and $\sim 18 \%>480 \mathrm{~s}$ ) (figures 4 and 5 ). For patients not achieving a baseline tLIM within 180-480 s, a practical strategy is to adjust the WR to bring tLIM within the desired range (i.e. $\pm 5 \mathrm{~W}$ ), and repeating the test [102]. Measurements of the curvature constant of the power-duration relationship in COPD patients $[26,105,110]$ support this approach, and suggest that 5-W adjustments (up or down) are sufficient to reset an initial tLIM between $\sim 120$ and $\sim 840$ s to within the recommended range in an additional $30 \%$ of the patients $[33,108,109]$. Additionally, 5-W adjustments are within the technical capacity of most cycle ergometers.

Safety

There have been no reports of adverse events while performing CWRETs. These tests are usually performed after an IET, which effectively serves as a prescreening for adverse reactions to exercise. While there is no specific information about the threshold at which arterial desaturation becomes hazardous, it has been recommended that the test should be terminated if $\mathrm{SpO}_{2}$ falls below $80 \%[3,17,18]$. 
CANTO, 2012 [284] VAN DER VAART, 2011 [285]

O'DONNELL, 2011 [101]

ZHANG, 2010 [286]

ZHANG, 2010 [287]

WORTH, 2010 [288]

NEDER, 2007 [289]

O'DONNELL, 2006 [100]

D'DONNELL, 2004 [62]

MAN, $2004[290]$

GUENNETTE, 2013 [291]

MAGNUSSEN, 2012 [292]

GUENNETTE, 2011 [293]

WORTH, 2010 [286]

O'DONNELL, 2006 [100]

BEEH, 2014 [118]

COOPER, $2013[294]$

YOSHIIMURA, 2012 [295]

BEEH, 2012 [296]

MALTAIS, 2011 [104]

VAN DER VAART, 2011 [285]

O'DONNELL, 2006 [100]

CASABURI, 2005 [297]

MALTAIS, 2005 [103]

O'DONNELL, 2004 [62]

BEEH, 2014 [118]

MAGNUSSEN, 2012 [292]

CANTO, 2012 [284]

BERTON, 2010 [117]

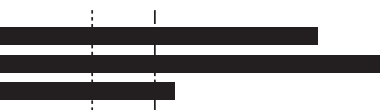

Subjects $\mathrm{n}$ FEV 1 L WR W


$\begin{array}{lll}38 & 39 & 80\end{array}$

$\begin{array}{lll}25 & 41 \quad 50\end{array}$

$90 \quad 61 \quad 75$

$20 \quad 55 \quad 85$

$111 \quad 38 \quad 75$

$21 \quad 39 \quad 80$

$108 \quad 42 \quad 75$

$\begin{array}{lll}23 & 42 & 75\end{array}$

b) First author, year [ref.]

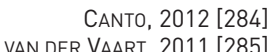
ZHANG, 2010 [286] ZHANG, 2010 [287] WORTH, 2010 [288] NEDER, 2007 [289]

O'DONNELL, 2006 [100] O'DONNELL, 2004 [62] MAN, 2004 [290] GUENNETTE, 2013 [291] MAGNUSSEN, 2012 [292] GUENNETTE, 2011 [293] WORTH, 2010 [288]

O'DONNELL, 2006 [100] BEEH, 2014 [118] COOPER, 2013 [294] YOSHIIMURA, 2012 [295] BEEH, 2012 [296] MALTAIS, 2011 [104] VAN DER VAART, 2011 [285]

O'DONNELL, 2006 [100]

CASABURI, 2005 [297]

MALTAIS, 2005 [103]

O'DONNELL, 2004 [62] BEEH, 2014 [118] MAGNUSSEN, 2012 [292 CANTO, 2012 [284] BERTON, 2010 [117]



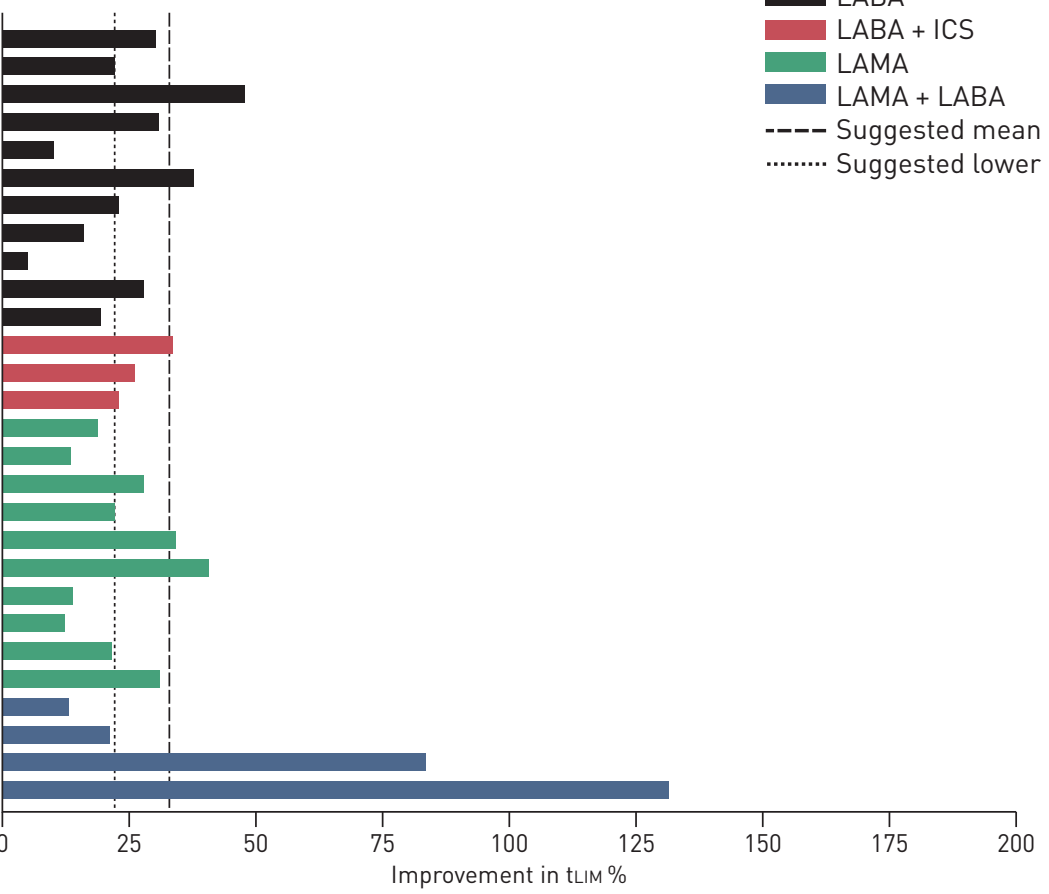

FIGURE 3 a) Absolute and b) percentage changes in time to the limit of tolerance (tLIM) in constant work-rate exercise test studies using a cycle ergometer in relation to placebo in studies with long-acting $\beta_{2}$-adrenoceptor agonists (LABA), long-acting antimuscarinics (LAMA), inhaled corticosteroids (ICS) and their combination in chronic obstructive pulmonary disease patients. Descriptive data for individual studies are shown only once. FEV1: forced expiratory volume in $1 \mathrm{~s}$; WR: work-rate; MCID: minimum clinically important difference. ${ }^{\#}$ : suggested mean MCID thresholds a) $105 \mathrm{~s}$, b) $33 \%$; ${ }^{\text {? }}$ : suggested lower limit of $95 \%$ CI MCID thresholds a) 60 s, b) $22 \%$ [102].

Tolerance time

Tolerance time for a CWRET is the duration from the WR imposition to the point of task failure. Due to the curvature of the WR-tLIM relationship, tLIM (conventionally expressed in seconds or minutes) is a particularly sensitive index of interventional change in several respiratory diseases. 

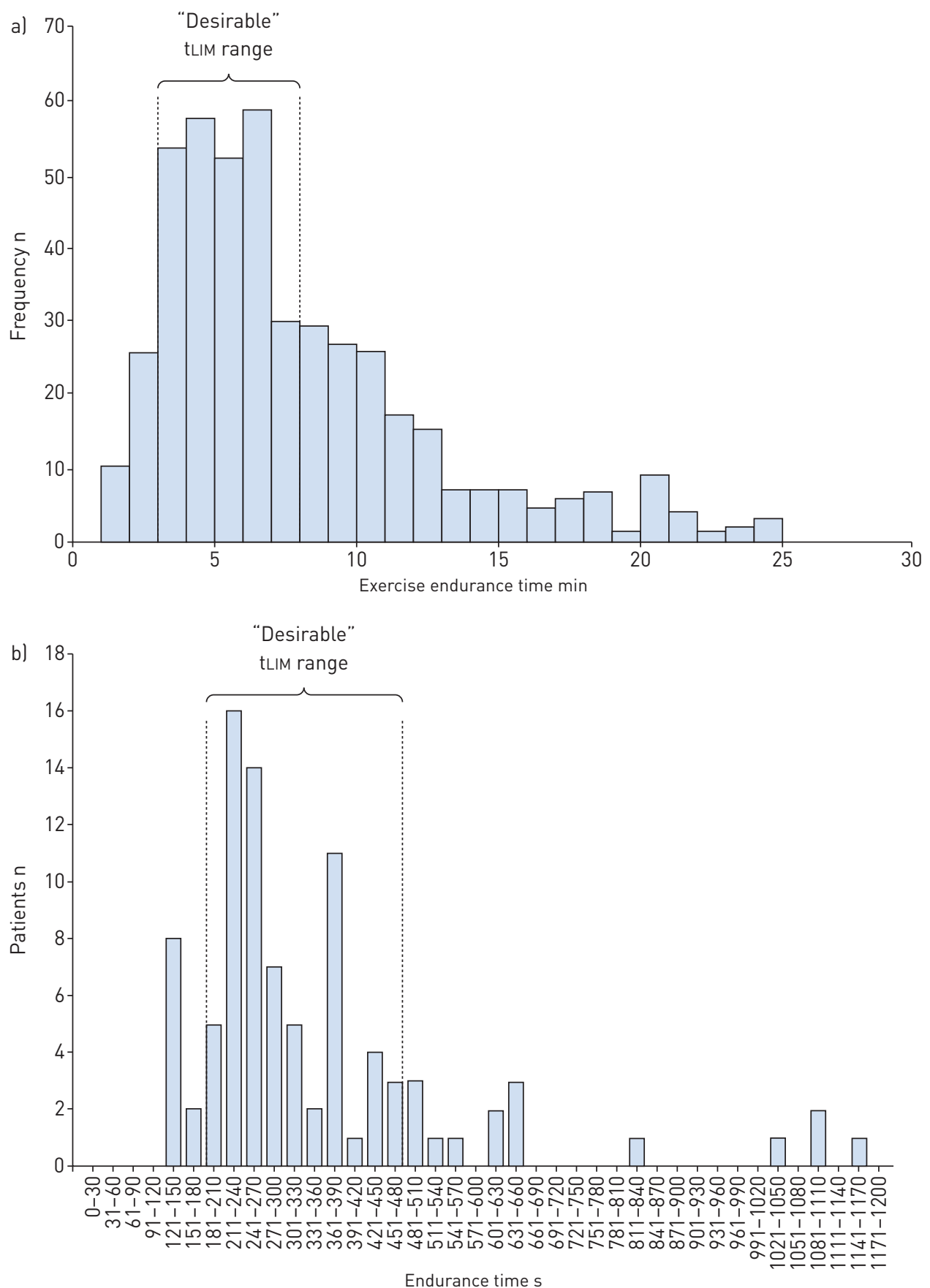

FIGURE 4 Endurance time (time to the limit of tolerance (tLIM)) variability in response to cycle ergometer constant work-rate exercise test performed at a) $75 \%$ and b) $80 \%$ of peak work-rate in moderate-to-severe chronic obstructive pulmonary disease patients. al $n=463$. Reproduced from [33] with permission from the publisher. b) n=92. Reproduced with permission [109].

\section{Validity}

In COPD patients the increase in tLIM following exercise training is likely to reflect improvements in the aerobic capacity of the trained muscles $[111,112]$ and a delayed onset of metabolic acidosis $[98,111,113]$, as well as slowed increases in operating lung volume and breathlessness [114, 115]. Interventions designed to improve ventilatory function (i.e. bronchodilators) also lead to an improved tLIM, probably because of the latter mechanism [116], although respiratory-muscle unloading may also improve oxygen supply to the lower-limb locomotor muscles [117].

Interventions able to improve tLIM are associated with increased health-related quality of life (HRQoL) $[25,101,102]$ and physical activity levels [118]. tLIM has been shown to perform consistently well as a 

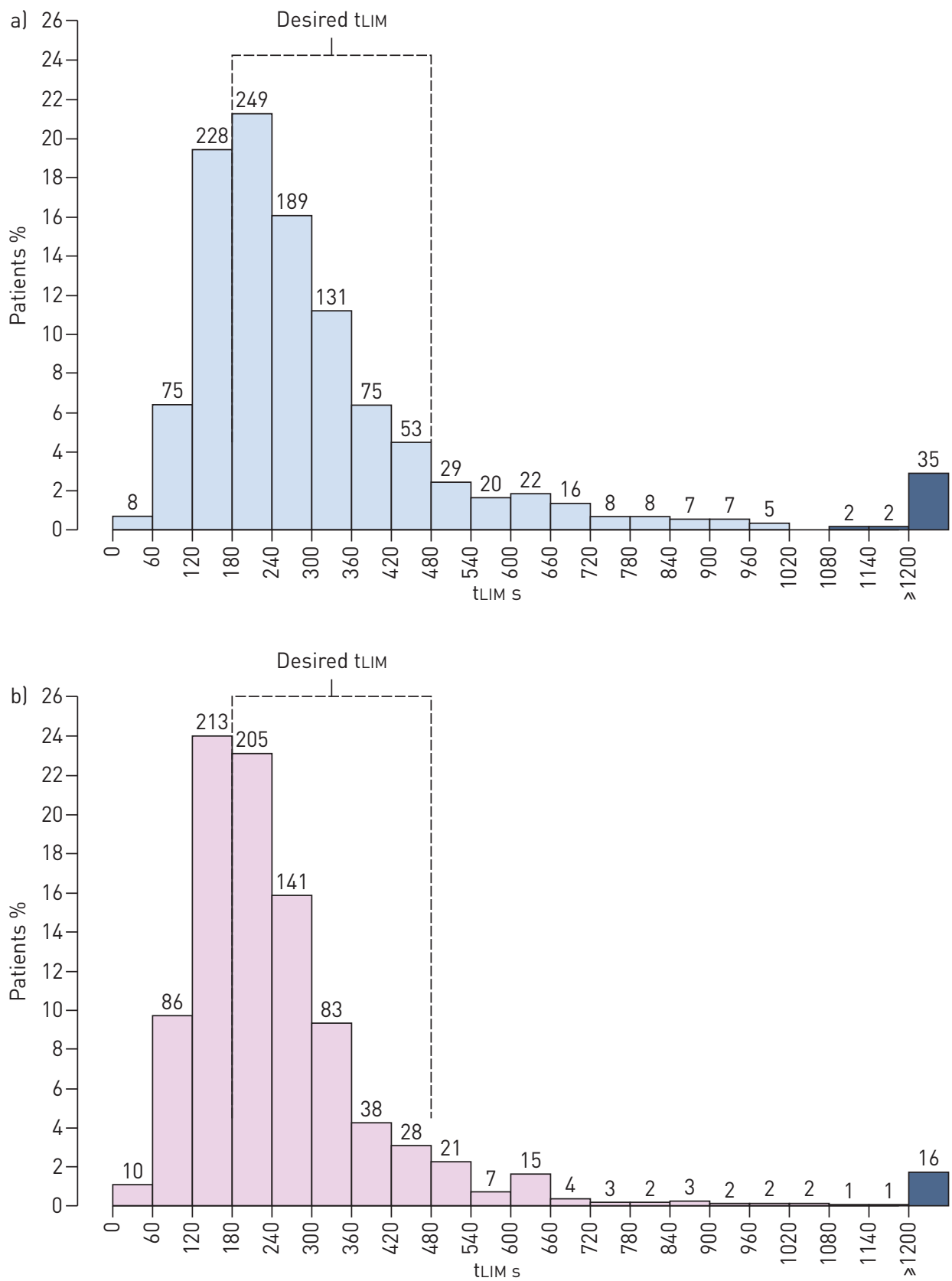

FIGURE 5 Endurance time (time to the limit of tolerance (tLIM)) variability in response to cycle ergometer constant work-rate exercise tests performed at $75 \%$ of peak work-rate in a large sample $(n=2053)$ of chronic obstructive pulmonary disease patients. a) Males; b) females. Reproduced and modified from [108] with permission from the publisher.

sensitive outcome variable among different laboratories in multicentre clinical trials, provided that quality-control procedures are implemented [33] (table 1).

\section{Precision}

Repeatability for tLIM was addressed in a multicentre trial of 463 COPD patients who performed two CWRETs 5 days apart [33]. There was a small but significant $(\mathrm{p}<0.001)$ increase of $34 \mathrm{~s}$ (coefficient of variation $24 \%$ ) in tLIM in the second CWRET, suggesting a small ordering effect. Nonetheless, the intraclass correlation coefficient (ICC) was 0.84 (95\% CI 0.81-0.87) [33] (table 2). A smaller ( 12 s) nonsignificant ordering effect and similar ICC were also found in two studies of 60 [106] and 25 [102] COPD patients, in which CWRET was repeated on the same day or the next day, respectively, in single laboratories with experience in CWRET $[102,106]$. The low mean difference and high ICC for repeated 
constant work-rate exercise tests suggests good to very good adherence for tests performed under identical conditions.

\section{Prognostic information}

To date, there are no studies establishing potential relationships between increase in tLIM and survival, healthcare costs or exacerbation rates (table 1).

\section{Discrimination}

Since one goal of the test design is to standardise tLIM and reduce intersubject variability, by design the CWRET tLIM is not discriminative. tLIM is designed to assess the efficacy of interventions.

\section{Clinically meaningful difference}

There is limited information on MCID for tLIM after interventions. In COPD, 100-s (95\% CI 60-140 s) or $33 \%$ (95\% CI 18-48\%) change from baseline using cycle ergometry related well with positive patient-reported outcomes after pulmonary rehabilitation [102, 119]. The use of MCID as a percentage appears to be less dependent on baseline tLIM when $75 \%$ and $85 \%$ of WRpeak were compared [102] (table 2). However, data from bronchodilator studies suggest that improvements in lung function that seem to be clinically important are often associated with increases of tLIM $<100 \mathrm{~s}$ (figures 2 and 3).

\section{Evaluation}

In COPD, tLIM is responsive to rehabilitative interventions, as well as to interventions aimed at unloading the respiratory system, such as breathing heliox, oxygen therapy, noninvasive ventilatory support (figure 1) and lung volume reduction surgery [120]. Most nonpharmacological interventions in COPD produce clinically important improvements in tLIM (i.e. a 100 -s or 33\% improvement was reached in 30 (91\%) out of 33 and $27(82 \%)$ out of 33 investigations, respectively) (figure 1). tLIM is also responsive to rehabilitation in idiopathic PAH $[121,122]$ and IPF $[123,124]$. In one observational study of 53 IPF patients, the effect size for tLIM after rehabilitation was larger than for $V^{\prime} \mathrm{O}_{2}$ peak, WRpeak, 6MWD and ISWT [123] (table 3). Oxygen therapy significantly increases tLIM by an average of 162 (95\% CI 118-207) $s$ in patients with COPD who desaturate during exercise [59]. Although there are very few studies on the effects of oxygen therapy on tLIM, in two studies a substantial improvement in tLIM was found [125]. Improvements in tLIM with oxygen therapy have also been reported in cystic fibrosis [58].

High-intensity CWRETs have been used to evaluate responses to short- and long-acting bronchodilators in COPD (figures 2 and 3, table 4). Only 14 (54\%) out of 26 studies of long-acting bronchodilators and three $(27 \%)$ out of 11 studies of short-acting bronchodilators showed average increases in tLIM $>100 \mathrm{~s}$. This proportion decreased to eight (31\%) out of 26 for long-acting bronchodilators if the criterion of 33\% improvement was used. An effect $>60$ s (the one-tailed lower confidence limit of the MCID calculated from [102]) was observed in $22(84 \%)$ out of 26 of the studies presented in figures 2 and 3 . An effect $>22 \%$ (the one-tailed lower confidence limit of MCID calculated from [102]) was seen in 20 (77\%) out of 26 of the studies (figures 2 and 3).

\section{"Isotime" responses}

Isotime responses are measurements of variables made at specific time points, typically during a CWRET. The analysis of responses at a standardised time pre- and post-intervention has proven valuable in the physiological interpretation of tLIM changes. Importantly, unlike tLIM, isotime responses are effort-independent. They include $V^{\prime} \mathrm{O}_{2}, V^{\prime} \mathrm{CO}_{2}, V^{\prime} \mathrm{E}$, inspiratory capacity, breathing pattern, dyspnoea, leg effort, muscle fatigue, cardiac output, heart rate and arterial lactate concentration $\left(\left[\mathrm{La}^{-}\right]_{\mathrm{a}}\right)$.

\section{Isotime responses other than inspiratory capacity and dyspnoea}

Validity

The physiological meaning of isotime measurements depends on the variable and intervention, but in general terms, isotime reduction in $V^{\prime} \mathrm{O}_{2}, V^{\prime} \mathrm{CO}_{2}, V^{\prime} \mathrm{E}$, leg effort, muscle fatigue and $\left[\mathrm{La}^{-}\right]_{\mathrm{a}}$ are considered markers of increased aerobic and decreased anaerobic energy transfer in the working muscles [98, 111, $113,126]$. A decrease in isotime $V^{\prime} \mathrm{E}$ may also be the consequence of reduced dead space volume to tidal volume ratio, because the metabolic and acid-base ventilatory demands of the task have been reduced or because the patient adopts a more efficient breathing pattern [45, 101, 114, 115, 118, 127].

\section{Precision}

In a sample of $463 \mathrm{COPD}$ patients in a multicentre trial, within-subject coefficient of variation for isotime $V^{\prime} \mathrm{O}_{2}$ was $8.2 \%$ and for isotime $V^{\prime} \mathrm{E}$ was $7.4 \%$ [33]. 
Prognostic information

No specific information has been obtained on the ability of isotime measurements to predict clinical outcomes.

\section{Discrimination}

No information is available on the ability of isotime measurements to stratify patients with respiratory diseases.

Clinically meaningful difference

MCID is not established for isotime measurements.

\section{Evaluative}

Isotime $V^{\prime} \mathrm{O}_{2}, V^{\prime} \mathrm{CO}_{2}$ and $V^{\prime} \mathrm{E}$, as well as cardiac output and $\left[\mathrm{La}^{-}\right]_{\mathrm{a}}$ and other variables are responsive to a number of interventions in COPD [25, 62, 98, 99, 120, 128-131] and in some other conditions such as cystic fibrosis [132] and PAH [122, 133]. Isotime comparisons are also responsive outcomes of interventions directed to train arm muscles [134-136].

Inspiratory capacity

In contrast to healthy individuals [137], in patients with expiratory airflow limitation, end-expiratory lung volume increases during exercise as expiratory time becomes reduced with increasing breathing frequency, a phenomenon called dynamic hyperinflation [137].

Inspiratory capacity is used increasingly as an outcome measure in clinical trials to test the efficacy of bronchodilators and other interventions $[62,99,101,114,115,118,120,129,130]$.

\section{Procedure}

Subjects are required to take a deep inspiration, after normal expiration, at predetermined intervals during exercise (typically every $2 \mathrm{~min}$ ). Dynamic hyperinflation can be also evaluated as the difference between inspiratory capacity at rest and during exercise $[33,138,139]$.

\section{Validity}

Peak negative oesophageal pressure during exercise inspiratory capacity manoeuvres is similar to that at rest, despite changes in inspiratory capacity [140]. This suggests that changes in inspiratory capacity during exercise are due to dynamic hyperinflation and not to reduced respiratory muscle capacity.

While exaggerated dyspnoea and exercise intolerance are multifactorial in COPD, dynamic hyperinflation is believed to be an important contributor to each [141]. Inspiratory capacity may be more sensitive than other lung function variables to changes in expiratory airflow limitation [62, 99, 142, 143]. Dynamic hyperinflation correlates with carbon dioxide retention and hypoxaemia during exercise [144, 145] and daily living activity in COPD patients [146].

It has been shown that inspiratory capacity can be reliably determined at isotime and peak exercise in multicentre clinical trials $[33,101,118,127]$.

\section{Precision}

Reported within-subject coefficient of variation is $12-20 \%$ for exercise inspiratory capacity, but precision is less for change in inspiratory capacity $(58-88 \%)[33,138,147]$. In one study, variability was found to be larger for manoeuvres performed at the beginning and close to the end of exercise [138].

Prognostic information

Dynamic hyperinflation during exercise predicts mortality [148].

\section{Discrimination}

On average, there is a tendency to greater dynamic hyperinflation with COPD severity [149]. However, there was a significant overlap among groups [149].

\section{Clinically meaningful difference}

Changes in inspiratory capacity $>0.14 \mathrm{~L}$ (or $4.5 \%$ predicted) are beyond the $95 \%$ confidence interval [150] and have been consistently associated with significantly increased tLIM in moderate-to-severe COPD patients (figure 6). 

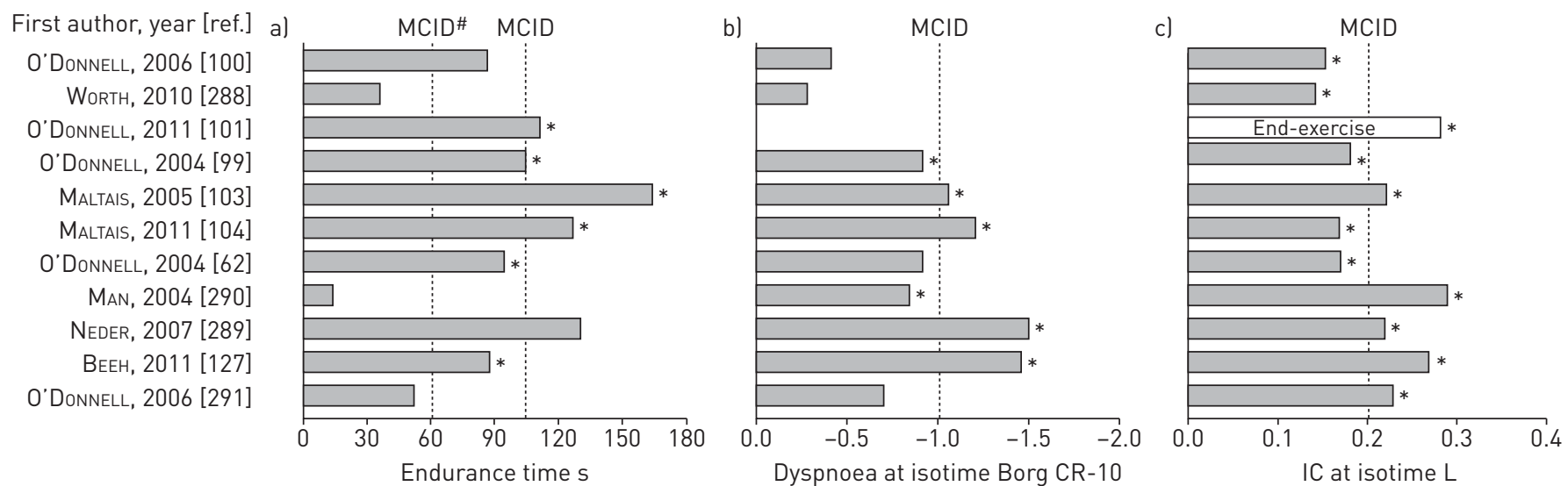

FIGURE 6 Relationships between the changes in a) endurance time (time to the limit of tolerance (tLIM)); b) dyspnoea at isotime; and c) isotime inspiratory capacity (IC) after the administration of bronchodilators. Mean minimal clinically important difference (MCID) thresholds of a) $105 \mathrm{~s}$; b) 1 point; and c) $0.2 \mathrm{~L}$. ${ }^{\#}$ : lower limit of $95 \% \mathrm{Cl} 60$ s.*: p<0.05.

\section{Evaluation}

Inspiratory capacity is responsive to change during exercise following numerous pharmacological (figure 6) and nonpharmacological interventions, including lung volume reduction and pulmonary rehabilitation [114, $115,120]$, with effects in the range of $0.2-0.3 \mathrm{~L}$ or $\sim 15 \%$ pred [139].

\section{Dyspnoea}

Dyspnoea is a characteristic symptom of most respiratory diseases. Two different approaches are used to measure dyspnoea: ratings based on daily living activities and ratings during specific exercise tasks. The information obtained by these two methods is different $[151,152]$. As the task force focused on exercise testing, the latter are discussed here.

\section{Procedure}

Dyspnoea is measured using either the 10-point Borg scale (CR-10) [153] or a 100-mm visual analogue scale (VAS) $[154,155]$. The CR-10 scale is derived from the original Borg 6-20-point perceived exertion scale (corresponding to a heart rate range of $60-200 \mathrm{bpm}$ ) [155, 156], modified to an open-ended 10-point scale including written indicators of severity to anchor specific numbers on the scale [153]. This was updated in 2010 with categories similar to the original 1982 scale, but having 19 points [155, 156]. In addition, a "modified CR-10 Borg scale", which is not open-ended, is frequently used [155, 156]. Readers should be aware that all of them are described (and frequently misquoted) as Borg or CR-10 scales in the literature [155].

Before exercise testing, subjects must be familiarised with the CR-10 or VAS, preferably by means of written instructions $[154,155]$. Dyspnoea should be measured at rest when the patient is ready to exercise, at least every $2 \mathrm{~min}$ during the test and at end-exercise [154, 155]. Symptom ratings should precede inspiratory capacity manoeuvres by at least five breaths to avoid interference [147]. End-exercise dyspnoea is quite variable among subjects $[110,152,157]$ and frequently patients rate it similarly after interventions $[26,62,99,101,118,127$, 131]; reflecting that exercise tolerance may have increased, exercise is often terminated at a similar intensity of dyspnoea. Thus, a more robust approach for comparing the effect of interventions on dyspnoea during IETs or CWRETs is to compare dyspnoea at isotime, or standardised for $V^{\prime} \mathrm{O}_{2}[158]$ or $V^{\prime} \mathrm{E}[158,159]$. Another method is comparing "dyspnoea slopes", i.e. the rating of dyspnoea as a function of time or WR during an IET [158].

\section{Validity}

The majority of respiratory patients experience dyspnoea during exercise [66, 99, 157, 160]. CR-10 or VAS dyspnoea ratings are subjective and therefore of most value when change within an individual is assessed. However, they are also used for intersubject comparisons [154, 155].

\section{Precision}

Dyspnoea ratings are reproducible in the short- and long-term [33, 154, 155, 161]. ICC for isotime and peak CR-10 are 0.79 and 0.81 , respectively [33].

\section{Prognostic information}

To our knowledge, neither isotime nor end-exercise dyspnoea scores have been specifically studied as predictive variables. 


\section{Discrimination}

Dyspnoea ratings are highly variable for the same effort among subjects with similar spirometric impairment $[33,154,155,157,161]$ and, probably because of that, no significant correlation between peak exercise dyspnoea and spirometric severity has been detected in COPD patients [162].

\section{Minimal important difference}

Using a distribution-based approach, differences of two points in the CR-10 and 10-20 mm for the VAS have been suggested as clinically relevant thresholds $[154,155]$. However, some propose that since the CR-10 scale is not strictly linear (yet is designed with ratio properties), smaller changes of the order of 1.0 can be considered relevant for less intensive interventions (i.e. acute response to oxygen therapy or bronchodilator therapy) [163] (figure 6).

\section{Evaluation}

Isotime dyspnoea, as measured by the CR-10 and VAS scales, is sufficiently sensitive to evaluate therapeutic interventions in COPD patients $[45,62,99,101,118,120,127,129,131]$. However, that improvements in patient-reported dyspnoea with bronchodilator therapy during CWRETs are variable is probably due to measurement variability in this outcome as well as the modest numbers of patients in several of these studies [156]. Oxygen therapy significantly reduces dyspnoea (CR-10) by a pooled mean of -1.15 (95\% CI $-1.65--0.65)$ in COPD patients who desaturated during exercise [128]; and a statistically significant, but clinically very small, effect in mildly or nonhypoxaemic COPD patients who are dyspnoeic at rest, i.e. -0.37 (95\% CI $-0.50-0.24)$ [164]. In patients with ILD, also dyspnoeic at rest, the effects of ambulatory oxygen therapy on dyspnoea (CR-10) in hypoxaemic [165] and nonhypoxaemic subjects parallel those described for COPD [166].

\section{Field tests}

These simple exercise tests require less technical equipment than laboratory-based tests; therefore, they are cheaper, but at the expense of obtaining less physiological information. However, with recently available portable (although costly) equipment, it is now possible to perform field tests with full cardiopulmonary physiological monitoring. The most common field tests are the 6MWT, the ISWT and ESWT. Their metabolic (i.e. $V^{\prime} \mathrm{O}_{2}$ ) profiles differ considerably (figure 7), highlighting the differences between them.

\section{Safety}

Field tests are generally safe. A specific report of complications associated with premature termination of the $6 \mathrm{MWT}$ indicated a $6 \%$ occurrence, with oxygen desaturation being the most common $(\sim 5 \%)$, followed by "symptoms" $(\sim 1 \%)$ and chest pain and tachycardia $(<1 \%)$ [167]. Both 6MWT and ISWT are used in $\mathrm{PAH}$ patients with no severe problems being reported [66]. Nonetheless, the available evidence shows that in both COPD and ILD patients, 6MWT typically elicits $V^{\prime} \mathrm{O}_{2}$ and heart rate responses as high as $85-90 \%$ of the cycle ergometer IET peak, and not infrequently, even greater values are achieved [168, 169]. This also seems to be the case in most PAH patients [170]. For ISWT, $V^{\prime} \mathrm{O}_{2}$ and heart rate responses approach peak cycle ergometer IET values $[168,171]$ (figure 7 ). Therefore, there is no rationale for considering risk mitigation in field testing compared to maximal laboratory exercise tests. As such, the degree of monitoring typically undertaken for an IET (i.e. ECG monitoring (direct or telemetric) or pulse oximetry) would be expected to enhance safety in field tests (table 1).

FIGURE 7 Oxygen uptake $\left(\mathrm{V}^{\prime} \mathrm{O}_{2}\right)$ profile in three different exercise tests in eight chronic obstructive pulmonary disease patients. al 6-min walk test; b) incremental shuttle walk test (ISWT); and c) incremental cycle ergometer exercise test (IET). Although the IET and ISWT involve different exercise modalities and active muscle masses, a similar peak $V^{\prime} \mathrm{O}_{2}$ is attained. Reproduced and modified from [168] with permission from the publisher.

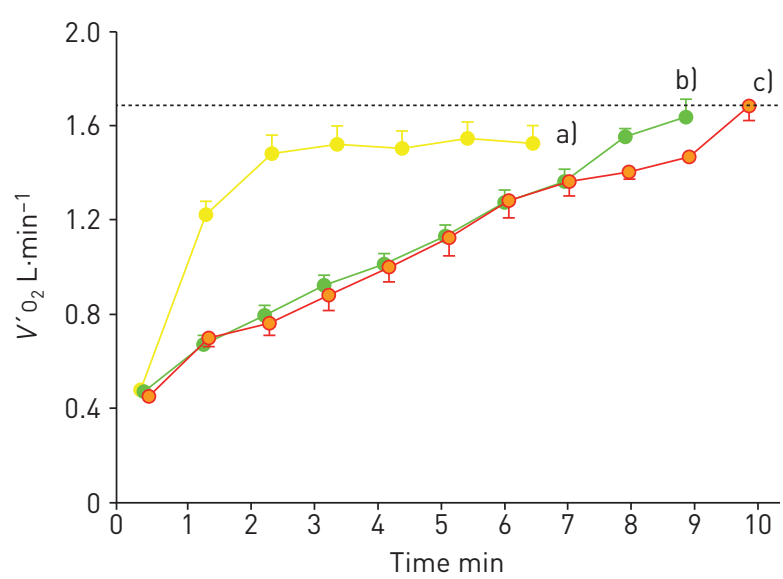


The ESWT is usually performed after an ISWT, and so is likely to be safer than the ISWT because contraindications to exercise testing may have been identified in the prior test.

Reasons to stop the test, and contraindications to exercise, are identical to the IET recommendations [3, 18]. While there is no information about the risks of desaturation, it is recommended that tests be terminated if $\mathrm{SpO}_{2}$ falls to $<80 \%$ [172].

\section{Shuttle walk tests}

Incremental shuttle walk test

The ISWT (table 1) is an externally paced incremental walking test [173]. The ISWT has been shown to be feasible in a wide variety of populations, including patients with COPD [174], ILD [175] and in children with cystic fibrosis [176].

\section{Procedure}

Subjects are required to walk around two markers $9 \mathrm{~m}$ apart (10 m course). Single audio cues (beeps) signal the time at which the subject is expected to turn at the marker. Walking speed is increased each minute. The ISWT has 12 levels (walking speeds) and therefore lasts a maximum of $12 \mathrm{~min}$. No encouragement is given during the test: the only verbal cues provided refer to an impending increase in walking speed [173]. ISWT performance is usually defined as the distance achieved. It is recommended to measure $\mathrm{SpO}_{2}$ and heart rate $[172,177]$ (table 1).

\section{Validity}

Available data suggest that ISWT distance correlates well $(\mathrm{r}=0.66-0.88)$ with measured IET $V^{\prime} \mathrm{O}_{2}$ peak in a variety of respiratory conditions [172]. Furthermore, the metabolic response profile is comparable to IET values [168] (figure 7). ISWT distance has been shown to be correlated significantly with daily living activity $(\mathrm{r}=0.17-0.58)$ [32, 172], with quadriceps muscle strength $(\mathrm{r}=0.47)$ and with forced expiratory volume in $1 \mathrm{~s}(\mathrm{FEV} 1)$ and age in severe COPD, but not with muscle mass or body mass index [178]. ISWT distance accounted for 55\% of the variability of St George's Respiratory Questionnaire total score and 53\% of Short-Form (SF)-36 [179]. The ISWT has been used in a multicentre clinical trial [180].

\section{Precision}

On average, there is a small $(20-25 \mathrm{~m})$, but statistically significant, increase between the first two ISWTs performed on the same day or on different days [172, 181]. To ensure reproducible results when evaluating responses to interventions, the recommendation is that two ISWTs be performed at baseline and the greatest distance recorded.

\section{Prognostic information}

The ISWT is a significant predictor of survival and readmission in COPD patients $[182,183]$ (table 2).

\section{Discrimination}

There is no information about whether ISWT is discriminative in respiratory diseases. ISWT distance demonstrates a mild correlation with $\mathrm{FEV}_{1}$ [178]. In one study of COPD patients, walking $<170 \mathrm{~m}$ on an IWST was associated with greater mortality [183].

\section{Clinically meaningful difference}

The MCID value for the ISWT was set at $47 \mathrm{~m}$ [180, 184], with additional benefits reported at $79 \mathrm{~m}$ [184] (table 2).

\section{Evaluation}

In COPD the ISWT is usually sensitive to rehabilitative interventions (figure 8). In a recent meta-analysis of nine trials, a mean improvement of $38 \mathrm{~m}(95 \%$ CI 22-51 m) was found [73]. In COPD patients recovering from a stay in the intensive care unit, ISWT was found to improve by a mean of $64 \mathrm{~m}$ after rehabilitation [185].

ISWT detected small improvements after oxygen therapy in COPD patients with exercise desaturation $[186,187]$ (table 3).

ISWT is sensitive to both short- and long-acting anticholinergic and $\beta_{2}$-agonist bronchodilators in COPD in most [172, 177, 188-190], but not all [191] studies. The mechanisms of improvement have not been studied extensively, but are probably related to improvements in lung function [189, 190]. In non-cystic fibrosis bronchiectasis patients, treatment of exacerbations with 14 days of intravenous antibiotics significantly improved ISWT performance [192] (table 4). 


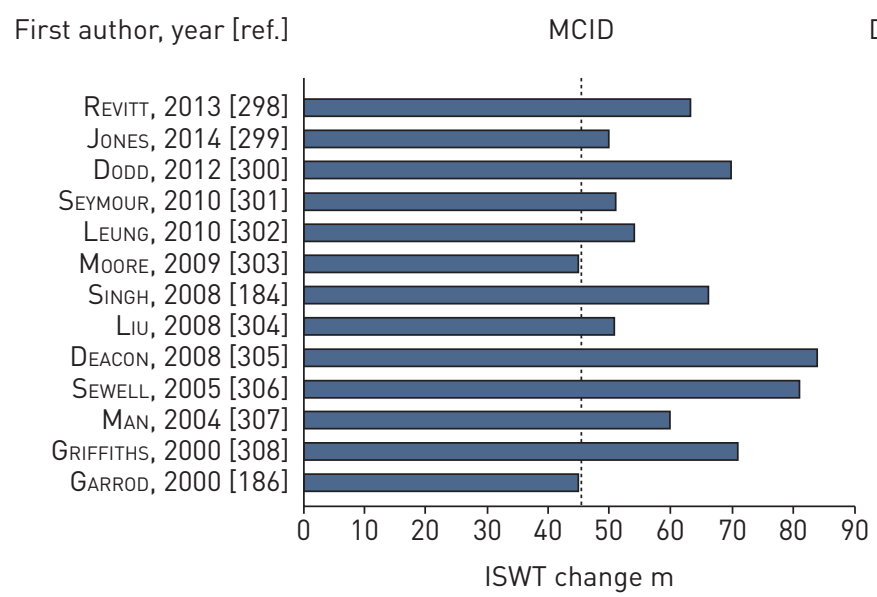

\begin{tabular}{ccc}
$\begin{array}{c}\text { Duration } \\
\text { weeks }\end{array}$ & \multicolumn{1}{c}{ Type } & $\begin{array}{c}\text { Patients } \\
n\end{array}$ \\
7 & Hospital outpatients & 372 \\
7 & Hospital outpatients & 180 \\
6 & Home & 45 \\
6 & Hospital outpatients & 2000 \\
7 & Hospital outpatients & 100 \\
7 & Hospital outpatients & 160 \\
8 & Hospital outpatients & 45 \\
8 & Hospital outpatients & 42 \\
8 & Hospital outpatients & 60 \\
8 & Hospital outpatients & 36 \\
8 & Hospital outpatients & 239 \\
8 & Hospital outpatients & 261 \\
8 & Home-based & 48 \\
& & \\
& &
\end{tabular}

FIGURE 8 Change in incremental shuttle walk test (ISWT) distance in a selection of studies using ISWT as an outcome following rehabilitation. MCID: minimal clinically important difference (47 m).

\section{Endurance shuttle walk test}

The ESWT [193] is derived from the ISWT, in much the same way as the laboratory CWRET derives from the IET. Like the ISWT, it is externally paced and its intensity is tailored to the exercise tolerance of the individual patient (table 1).

\section{Procedure}

The ESWT uses the same course and auditory signal method as the ISWT; however, a constant walking cadence is maintained throughout the test. The ESWT starts with a 100-s "warm-up" at a slow pace [193], followed by the "exercise" phase at the prescribed speed (typically $80 \%$ of peak ISWT) calculated from a previous ISWT result [193]. Results are expressed in seconds or in metres.

As the considerations of the velocity-duration curve for the ESWT are essentially identical to those of the CWRET power-duration curve, interindividual variability of test duration is expected to be high, unless the duration is purposely standardised. Thus, coefficient of variations have been reported to range between $60 \%$ and $120 \%$ of the corresponding means [174, 194-198]. While no recommendation on how to adjust test duration has yet been proposed, it is reasonable to assume that the range of baseline test durations used for the CWRET is desirable (i.e. 180-480 s) (table 1).

Validity

There is little information on the mechanisms determining baseline ESWT duration. It is likely that the physiological determinants are analogous to those of CWRET (online supplementary material), although some evidence suggests that ventilatory limitation may be more prominent in walking than in cycle ergometry. In a small group of moderate COPD patients, dyspnoea was reported more frequently during the ESWT than for cycle ergometry CWRET (70\% versus $41 \%$, respectively) [174]. In COPD patients, ESWT duration moderately correlates with FEV1 $(\mathrm{r}=0.44, \mathrm{p}<0.001)$, but not with measures of muscle mass or strength [178]. In one small study in older individuals, ESWT was found to be limited by a ceiling effect and could not be performed successfully in approximately half the patients [199]. The test has been used in multicentre clinical trials $[198,200]$.

\section{Precision}

In the original study defining the ESWT, a significant ordering effect between first and second ESWT attempts was observed (an increase of $59 \mathrm{~s}$ or $47 \mathrm{~m}$ ). However, subsequent reports showed that differences between tests performed on different days were lower (e.g. $15 \mathrm{~s}$ ) and nonsignificant [194, 201, 202]. In a recent multicentre clinical trial involving 255 moderate-to-severe COPD patients, the mean \pm sD differences between the first two ESWT performances $(-7 \pm 72 \mathrm{~s}$ and $-7 \pm 113 \mathrm{~m}$ for endurance time and distance, respectively) were not statistically significant [194] (table 2).

\section{Prognostic information}

There is no information about changes in ESWT having prognostic value for variables such as survival, exacerbations or healthcare burden. 
Discrimination

Since one goal of the ESWT design is to standardise the initial duration to reduce its intersubject variability, it is anticipated that ESWT will not provide additional discriminative information to the ISWT needed to set the test speed.

\section{Clinical meaningful difference}

A few studies have addressed the MCID for change in ESWT in response to interventions in COPD. Employing an anchor-based approach, it was not possible find a valid estimation of the MCID for ESWT following pulmonary rehabilitation [174]. For pharmacotherapies (salmeterol and ipratropium), an MCID of change in ESWT duration of $65 \mathrm{~s}$ was found (95\% CI 45-85 s), equivalent to $95 \mathrm{~m}$ (95\% CI 60-115 m). These ESWT changes represented $13-15 \%$ of baseline values. These figures were confirmed by the same authors in a multicentre trial including 255 patients in which changes of 56-61 s and 70-82 $\mathrm{m}$ in ESWT were perceived by the participants as relevant [194] (table 2).

\section{Evaluation}

ESWT is responsive to pulmonary rehabilitation in patients with COPD (the pooled mean of studies in figure 9 is $\sim 360 \mathrm{~s}$ ), bronchiectasis [203] and IPF [175] (table 3). ESWT is also responsive to oxygen therapy in patients with COPD [204] and IPF [175] who desaturate during exercise.

Experience with ESWT to evaluate response to bronchodilators is more limited than with CWRET (table 4). Significant changes are seen with short- and long-acting anticholinergics or salmeterol in COPD patients, with improvements between $70 \mathrm{~s}$ and $164 \mathrm{~s}$ [174, 195-198]. In contrast, the MCID for ESWT was not reached with ipratropium in one study of patients with mild COPD [205] and in the post hoc integrated data analysis of two studies with the fixed combination umeclidinium/vilanterol (55/22 $\mu \mathrm{g})$ [198].

In idiopathic PAH patients, ESWT distance was not increased by sildenafil, but 6MWD did increase [206].

\section{6-min walk test}

The 6MWT is the result of the evolution of a previous test aimed to assess functional capacity by measuring distance walked in a controlled length of time. A 6-min duration was found to be the best compromise between variability and length, while remaining discriminative [207].

\section{Procedure}

The 6MWT measures the distance that an individual can walk on an indoor $30-\mathrm{m}$ flat corridor for a 6-min period [172]. Tracks $<15 \mathrm{~m}$ have been shown to reduce 6MWD [208]. Due to a distinct familiarisation effect $[172,177,209,210]$, a minimum of two tests should be performed, with at least $15 \mathrm{~min}$ of intervening rest, with the greatest distance in the two tests being recorded $[172,177]$. 6MWD is expressed in metres or feet $[172,177]$. Other variables such as minimum $S_{\mathrm{pO}_{2}}$, peak heart rate and dyspnoea and fatigue ratings can be measured $[172,177]$.

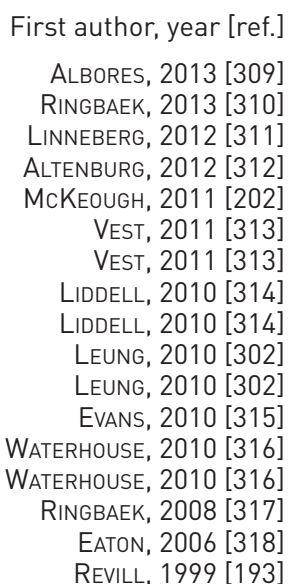

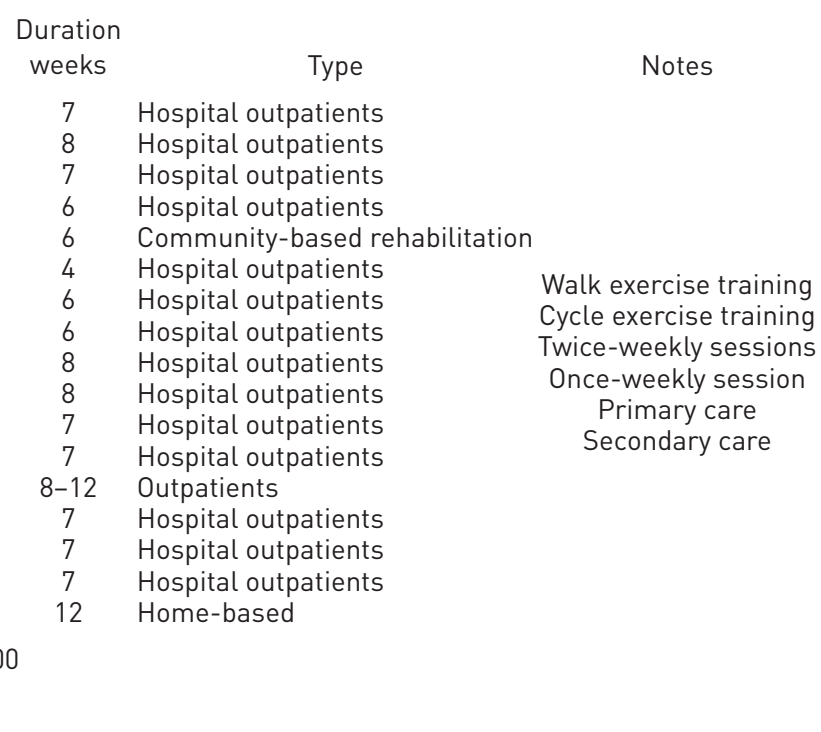

FIGURE 9 Improvement in endurance shuttle walk test (ESWT) performance (time in seconds) in chronic obstructive pulmonary disease patients following pulmonary rehabilitation. 
Validity

In several studies of COPD, PAH and ILD patients, 6MWD correlates with IET $V^{\prime} \mathrm{O}_{2}$ peak and WRpeak [170, 211-215]. In the largest study to date (2906 COPD patients), the correlation between 6MWD and WRpeak was 0.67 [214]. 6MWD correlates $(\mathrm{r}=0.40-0.65)$ with FEV 1 in COPD [213, 215-217]. In IPF, 6MWD does not appear to show significant correlation with either forced vital capacity or transfer factor of the lung for carbon monoxide [211, 218, 219] (table 1). In PAH, 6MWD correlates with resting cardiac output and PVR [212], New York Heart Association Functional Class [212] and HRQoL [220]. Similarly, 6MWD change following PAH treatment correlated with changes in cardiac index, PVR [221] and HRQoL [220]. However, it has proven very difficult to demonstrate any prognostic power of 6MWD change with therapy. In a meta-analysis of $22 \mathrm{PAH}$ treatment studies, neither the change in haemodynamics nor 6MWD predicted subsequent clinical events [221]. In a pooled analysis of $10 \mathrm{PAH}$ treatment studies submitted to the FDA (2404 patients), despite a significant improvement in 6MWD, this accounted for only $22.1 \%$ of the treatment effect; the authors concluded that it was, at best, a modest surrogate end-point for clinical events [222]. 6MWD also correlates with physical activity $(r=0.40-0.85)$ [223-225] and with HRQoL and daily living dyspnoea $(\mathrm{r}=0.25-0.50)[213,216,219]$. The $6 \mathrm{MWT}$ is a more sensitive test for identifying exercise-induced desaturation than the cycle ergometer IET [226]. It has been widely used in multicentre studies of respiratory patients $[42,172,177,219,227,228]$, and is the only test that has been used so far in IPF clinical trials $[219,228]$. However, the $6 \mathrm{MWT}$ has a ceiling effect as the linear relationship between IET $V^{\prime} \mathrm{O}_{2}$ peak and 6MWD is lost in less impaired patients $[229,230]$.

Precision

When the $6 \mathrm{MWT}$ is performed twice, $6 \mathrm{MWD}$ is reproducible, with ICC $>0.70$, with a coefficient of variation range of $5-8 \%$ for COPD, ILD and cystic fibrosis [172, 177] (tables 1 and 2).

\section{Prognostic information}

Of any testing format, the 6MWT has the most comprehensive prognostic information available in most chronic respiratory diseases $[172,177]$ (table 1 ). Several of the variables measured, such as 6MWD [172, 177], desaturation in IPF [231, 232] and impaired heart rate recovery in IPF [231] and PAH [233] have been found to be predictive of survival. In COPD, 6MWD is also related to hospital admissions [234] (table 1).

\section{Discrimination}

In a large COPD cohort, 6MWD was related to the severity of obstruction, although there was considerable overlap between GOLD obstruction stages [227]. In addition, 6MWD can stratify the risk of mortality in COPD [235] and is part of the commonly recommended BODE (body mass index, airflow obstruction, dysponea, exercise capacity) index [1].

\section{Clinically meaningful difference}

Two recent documents issued by the ERS and American Thoracic Society concluded that the MCID lies between 25 and $33 \mathrm{~m}$, independent of disease [172, 177] (table 2). Given the poor performance of 6MWD change in predicting clinical outcomes in PAH [43, 221, 222], the use of MCID may be of limited significance, and values of 6MWD associated with better prognosis (380 $\mathrm{m}$ as suggested in one study [236], or $440 \mathrm{~m}$ as suggested by the REVEAL (Registry to Evaluate Early and Long-term Pulmonary Arterial Hypertension Disease Management) registry [237]) can be better targets for assessing the effectiveness of treatment [43]. This might also be the case for other respiratory diseases if exercise is used as a surrogate of survival.

\section{Evaluation}

Nonpharmacological interventions

According to a meta-analysis of rehabilitative interventions in COPD (including 38 trials), the mean effect of rehabilitation on 6MWD is 44 (95\% CI 33-55) m comparing treatment and control groups [72, 238].

The $6 \mathrm{MWT}$ has been used frequently to assess the effects of pulmonary rehabilitation. According to a meta-analysis of rehabilitative interventions in COPD (including 38 trials), the mean effect of rehabilitation on $6 \mathrm{MWD}$ is $44 \mathrm{~m}(95 \% \mathrm{CI} 33-55 \mathrm{~m})$ comparing treatment and control groups [73]. In a review of rehabilitation after a COPD exacerbation (including six trials), the mean effect was $78 \mathrm{~m}$ (95\% CI 12-143 m) comparing treatment and control groups [185]. Nonetheless, the limited comparative information available suggests that 6MWT is less responsive than cycle ergometer CWRET tLIM in assessing the effects of pulmonary rehabilitation in COPD [119]. Responses greater than the MCID were observed in 57\% of the participants with CWRET tLIM, but only in 27\% with 6MWD [119]. Other interventions in COPD for which 6MWD has been shown to be responsive are inspiratory muscle training [239], lung volume reduction surgery [240] and oxygen therapy [241], with improvements of 50-95 $\mathrm{m}$ in distance walked. 
A meta-analysis of two trials comparing exercise training with control groups in IPF showed statistically significant improvement of 6MWD of $39 \mathrm{~m}$ (95\% CI 15-62 m) [242], and a recent systematic review of rehabilitation in ILD reported a mean overall improvement of $44 \mathrm{~m}(95 \%$ CI 26-63 m) and $36 \mathrm{~m}$ (95\% CI 16-55 m) in patients with IPF [50]. 6MWD was also shown to improve after rehabilitation in idiopathic and thromboembolic PAH patients [121, 243, 244]. In these studies, control groups usually deteriorated, resulting in differences between the rehabilitation and control groups of $80-110 \mathrm{~m}$ (table 3). In COPD, oxygen therapy improves 6MWD by $12-59 \mathrm{~m}$ in hypoxaemic patients. This difference is larger $(17-109 \mathrm{~m})$ when the control is walking with compressed air rather than breathing ambient air, because of the weight handicap [172]. In one retrospective ILD study, the 29 patients not on oxygen therapy prior to testing walked a mean distance of $81.2 \mathrm{~m}$ further using optimal ambulatory oxygen $(\mathrm{p}=0.01)$, while the 41 patients already on domiciliary oxygen walked a mean distance of $16.9 \mathrm{~m}(\mathrm{p}=0.02)$ [245]. In another retrospective study of 52 patients with ILD who desaturated on exercise, oxygen therapy increased 6MWD ( 30 m, p=0.01) [165].

\section{Pharmacological interventions}

The 6MWT has a low responsiveness for evaluating bronchodilator interventions in COPD: most studies report changes in $6 \mathrm{MWD}$ with bronchodilation that are below the MCID value. These range from 20 to $42 \mathrm{~m}$ with short-acting $\beta_{2}$-agonists $[60,246]$, from 6 to $39 \mathrm{~m}$ with short-acting anticholinergics $[60,247]$, from 21 to $54 \mathrm{~m}$ with long-acting $\beta_{2}$-agonists $[239,248,249]$ and $\sim 10 \mathrm{~m}$ with long-acting anticholinergics [250].

In a systematic review of 26 randomised clinical trials $(n=3519)$, pooled mean increase in 6WMD for prostacyclin analogues (nine trials) was $35 \mathrm{~m}(95 \%$ CI $17-53 \mathrm{~m})$, for endothelin receptor antagonists (eight trials) $46 \mathrm{~m}$ (95\% CI 38-54 m) and for phosphodiesterase-5 inhibitors (six trials) $34 \mathrm{~m}$ (95\% CI 25-43 m) [251]. Pooled 6WMD increase for all three drug types (23 trials) was $38 \mathrm{~m}$ (95\% CI 30-47 m) [251]. In one small study, 6MWD was found to be more responsive than ESWT distance or CWRET tLIM in PAH patients taking sildenafil [206].

The pooled analysis of the studies PIPF-004 and PIPF-006 showed that after 72 weeks of treatment with pirfenidone there was a statistically significant difference in 6MWD between treatment and control groups of $24 \mathrm{~m}(\mathrm{p}<0.001)$, just below the MCID [228].

\section{Conclusion}

In respiratory patients, exercise testing is useful in the clinical and research setting to assess the effects of interventions. It also allows appraisal of the degree and mechanisms of impairment, and it is a strong independent prognostic factor. Several methods for evaluating exercise capacity are available. The severity and cause of exercise intolerance are best assessed by conducting standardised laboratory exercise testing in which detailed physiological measurements are made while patients perform cycle ergometry or treadmill walking. Protocols can be either constant ("endurance") or incremental. Simpler tests are also used, although the physiological information gathered is more limited: the 6MWT is relatively simple and has been used extensively; the ISWT and ESWT are better standardised and have been also used in several clinical trials. In COPD, endurance tests (i.e. CWRET and ESWT) are more responsive to interventions, both pharmacological and nonpharmacological, than incremental tests (i.e. IET and ISWT) and the 6MWT. The cycle ergometer CWRET has been used more extensively than the ESWT. It has the advantage that 1) the WR is precisely quantified; and 2) several physiological variables can be easily measured (e.g. inspiratory capacity and isotime responses), which allows elucidation and targeting of putative mechanisms of improvement or deterioration and which are responsive to interventions. Careful standardisation is necessary to reduce interindividual variability and economise sample size in clinical trials.

While a majority of bronchodilator studies show a relevant effect in enhancing the exercise capacity of COPD patients, a clinically relevant effect is not always found. Some of the inconsistency may be explained by differences in the mode and duration of action of bronchodilators; however, considerable variations may be due to inherent differences in study design or patients studied. In particular, the best method of assessing exercise tolerance requires further investigation before those bronchodilators which consistently improve exercise endurance can be fully appreciated.

The application of exercise testing to PAH has been dominated by the 6MWT, which has been used as surrogate measurement to obtain registration for most medications now used in that condition; however, the accumulated evidence suggests that change in 6MWD has little or no prognostic power and targeted absolute values are potentially better surrogates of changes in the natural history of the disease. Both $V^{\prime} \mathrm{O}_{2}$ peak and indices of the $V^{\prime} \mathrm{E}-V^{\prime} \mathrm{CO}_{2}$ relationship are also useful targets for treatments. Limited evidence suggests that $V^{\prime} \mathrm{O}_{2}$ peak may be a better predictor of the time to clinical deterioration. 
Less information about exercise testing in other chronic respiratory conditions is available, but being a strong predictor of survival and a source of information to understand the mechanisms of exercise intolerance, exercise testing appears as relevant for these as it is for COPD and PAH.

Exercise testing is generally safe. The available evidence does not favour any particular format as safer, and standard precautions must be adopted in all of them.

\section{Acknowledgements}

Thanks to Thomy Tonia (Institute of Social and Preventive Medicine, University of Bern, Bern, Switzerland) for her methodological advice, Valérie Rebeaud (Scientific Activities Department, European Respiratory Society, Lausanne, Switzerland) for her logistic assistance and Vasileios Andrianopoulos (Department of Research and Education, CIRO+, Centre of Expertise for Chronic Organ Failure, Eindhoven, the Netherlands) for his kind assistance with figure 5.

\section{References}

1 Celli BR, Cote CG, Marin JM, et al. The body-mass index, airflow obstruction, dyspnea, and exercise capacity index in chronic obstructive pulmonary disease. N Engl J Med 2004; 350: 1005-1012.

2 King TE Jr, Tooze JA, Schwarz MI, et al. Predicting survival in idiopathic pulmonary fibrosis: scoring system and survival model. Am J Respir Crit Care Med 2001; 164: 1171-1181.

3 ATS/ACCP Statement on cardiopulmonary exercise testing. Am J Respir Crit Care Med 2003; 167: 211-277.

4 Palange P, Ward SA, Carlsen $\mathrm{KH}$, et al. Recommendations on the use of exercise testing in clinical practice. Eur Respir J 2007; 29: 185-209.

5 Cote CG, Pinto-Plata VM, Marin JM, et al. The modified BODE index: validation with mortality in COPD. Eur Respir J 2008; 32: 1269-1274

6 Fell CD, Liu LX, Motika C, et al. The prognostic value of cardiopulmonary exercise testing in idiopathic pulmonary fibrosis. Am J Respir Crit Care Med 2009; 179: 402-407.

7 Lama VN, Flaherty KR, Toews GB, et al. Prognostic value of desaturation during a 6-minute walk test in idiopathic interstitial pneumonia. Am J Respir Crit Care Med 2003; 168: 1084-1090.

8 Marin JM, Carrizo SJ, Casanova C, et al. Prediction of risk of COPD exacerbations by the BODE index. Respir Med 2009; 103: 373-378.

9 Myers J, Prakash M, Froelicher V, et al. Exercise capacity and mortality among men referred for exercise testing. N Engl J Med 2002; 346: 793-801.

10 Oga T, Nishimura K, Tsukino M, et al. Analysis of the factors related to mortality in chronic obstructive pulmonary disease: role of exercise capacity and health status. Am J Respir Crit Care Med 2003; 167: 544-549.

11 Tojo N, Ichioka M, Chida M, et al. Pulmonary exercise testing predicts prognosis in patients with chronic obstructive pulmonary disease. Intern Med 2005; 44: 20-25.

12 Wensel R, Francis DP, Meyer FJ, et al. Incremental prognostic value of cardiopulmonary exercise testing and resting haemodynamics in pulmonary arterial hypertension. Int J Cardiol 2013; 167: 1193-1198.

13 Draft Guidance for Industry. Chronic Obstructive Pulmonary Disease: Developing Drugs for Treatment. Rockville, US Department of Health and Human Services Food and Drug Administration Center for Drug Evaluation and Research (CDER), 2007.

14 CHMP Guideline on the Clinical Investigations of Medicinal Products for the Treatment of Pulmonary Arterial Hypertension. London, EMEA/CHMP, 2008.

15 Guideline on Clinical Investigation of Medicinal Products in the Treatment of Chronic Obstructive Pulmonary Disease (COPD). London, EMEA/CHMP, 2012.

16 Guazzi M, Adams V, Conraads V, et al. EACPR/AHA Scientific Statement. Clinical recommendations for cardiopulmonary exercise testing data assessment in specific patient populations. Circulation 2012; 126: 2261-2274.

17 Palange $\mathrm{P}$, Carlone S, Forte S, et al. Cardiopulmonary exercise testing in the evaluation of patients with ventilatory $v s$ circulatory causes of reduced exercise tolerance. Chest 1994; 105: 1122-1126.

18 Wasserman K, Hansen JE, Sue DY, et al. Principles of Exercise Testing and Interpretation: Including Pathophysiology and Clinical Applications. 5th Edn. Philadelphia, Lippincott Williams \& Wilkins, 2011.

19 Palange $\mathrm{P}$, Forte S, Onorati P, et al. Ventilatory and metabolic adaptations to walking and cycling in patients with COPD. J Appl Physiol 2000; 88: 1715-1720.

20 Mahler DA, Gifford AH, Waterman LA, et al. Mechanism of greater oxygen desaturation during walking compared with cycling in patients with COPD. Chest 2011; 140: 351-358.

21 Porszasz J, Casaburi R, Somfay A, et al. A treadmill ramp protocol using simultaneous changes in speed and grade. Med Sci Sports Exerc 2003; 35: 1596-1603.

22 Davis JA, Whipp BJ, Lamarra N, et al. Effect of ramp slope on determination of aerobic parameters from the ramp exercise test. Med Sci Sports Exerc 1982; 14: 339-343.

23 Benzo RP, Paramesh S, Patel SA, et al. Optimal protocol selection for cardiopulmonary exercise testing in severe COPD. Chest 2007; 132: 1500-1505.

24 O’Donnell DE, Maltais F, Porszasz J, et al. The continuum of physiological impairment during treadmill walking in patients with mild-to-moderate COPD: patient characterization phase of a randomized clinical trial. PLoS One 2014; 9: e96574.

25 Puente-Maestu L, Sánz ML, Sánz P, et al. Comparison of effects of supervised versus self-monitored training programmes in patients with chronic obstructive pulmonary disease. Eur Respir J 2000; 15: 517-525.

26 Puente-Maestu L, SantaCruz A, Vargas T, et al. Effects of training on the tolerance to high-intensity exercise in patients with severe COPD. Respiration 2003; 70: 367-370.

27 Skalski J, Allison TG, Miller TD. The safety of cardiopulmonary exercise testing in a population with high-risk cardiovascular diseases. Circulation 2012; 126: 2465-2472.

28 Hansen JE, Sun XG, Yasunobu Y, et al. Reproducibility of cardiopulmonary exercise measurements in patients with pulmonary arterial hypertension. Chest 2004; 126: 816-824. 
Smith G, Reyes JT, Russell JL, et al. Safety of maximal cardiopulmonary exercise testing in pediatric patients with pulmonary hypertension. Chest 2009; 135: 1209-1214.

Balady GJ, Arena R, Sietsema K, et al. Clinician's guide to cardiopulmonary exercise testing in adults: a scientific statement from the American Heart Association. Circulation 2010; 122: 191-225.

Velloso M, Stella SG, Cendon S, et al. Metabolic and ventilatory parameters of four activities of daily living accomplished with arms in COPD patients. Chest 2003; 123: 1047-1053.

Zwerink M, van der Palen J, van der Valk P, et al. Relationship between daily physical activity and exercise capacity in patients with COPD. Respir Med 2013; 107: 242-248.

O'Donnell DE, Travers J, Webb KA, et al. Reliability of ventilatory parameters during cycle ergometry in multicentre trials in COPD. Eur Respir J 2009; 34: 866-874.

Oudiz RJ, Barst RJ, Hansen JE, et al. Cardiopulmonary exercise testing and six-minute walk correlations in pulmonary arterial hypertension. Am J Cardiol 2006; 97: 123-126.

Barst RJ, Langleben D, Frost A, et al. Sitaxsentan therapy for pulmonary arterial hypertension. Am J Respir Crit Care Med 2004; 169: 441-447.

McKone EF, Barry SC, FitzGerald MX, et al. Reproducibility of maximal exercise ergometer testing in patients with cystic fibrosis. Chest 1999; 116: 363-368.

Miki K, Maekura R, Hiraga T, et al. Impairments and prognostic factors for survival in patients with idiopathic pulmonary fibrosis. Respir Med 2003; 97: 482-490.

Pianosi P, Leblanc J, Almudevar A. Peak oxygen uptake and mortality in children with cystic fibrosis. Thorax 2005; 60: 50-54.

Deboeck G, Scoditti C, Huez S, et al. Exercise testing to predict outcome in idiopathic versus associated pulmonary arterial hypertension. Eur Respir J 2012; 40: 1410-1419.

Sun XG, Hansen JE, Oudiz RJ, et al. Exercise pathophysiology in patients with primary pulmonary hypertension. Circulation 2001; 104: 429-435.

Thirapatarapong W, Armstrong HF, Thomashow BM, et al. Differences in gas exchange between severities of chronic obstructive pulmonary disease. Respir Physiol Neurobiol 2013; 186: 81-86.

Puhan MA, Chandra D, Mosenifar Z, et al. The minimal important difference of exercise tests in severe COPD. Eur Respir J 2011; 37: 784-790.

McLaughlin VV, Gaine SP, Howard LS, et al. Treatment goals of pulmonary hypertension. J Am Coll Cardiol 2013; 62: Suppl. 25, D73-D81.

Corhay JL, Nguyen D, Duysinx B, et al. Should we exclude elderly patients with chronic obstructive pulmonary disease from a long-time ambulatory pulmonary rehabilitation programme? J Rehabil Med 2012; 44: 466-472. Casaburi R, Porszasz J, Burns MR, et al. Physiologic benefits of exercise training in rehabilitation of patients with severe chronic obstructive pulmonary disease. Am J Respir Crit Care Med 1997; 155: 1541-1551.

Maltais F, LeBlanc P, Jobin J, et al. Intensity of training and physiologic adaptation in patients with chronic obstructive pulmonary disease. Am J Respir Crit Care Med 1997; 155: 555-561.

Vogiatzis I, Williamson AF, Miles J, et al. Physiological response to moderate exercise workloads in a pulmonary rehabilitation program in patients with varying degrees of airflow obstruction. Chest 1999; 116: 1200-1207.

Chan L, Chin LM, Kennedy M, et al. Benefits of intensive treadmill exercise training on cardiorespiratory function and quality of life in patients with pulmonary hypertension. Chest 2012; 143: 333-343.

Grünig E, Lichtblau M, Ehlken N, et al. Safety and efficacy of exercise training in various forms of pulmonary hypertension. Eur Respir J 2012; 40: 84-92.

Dowman L, Hill CJ, Holland AE. Pulmonary rehabilitation for interstitial lung disease. Cochrane Database Syst Rev 2014; 10: CD006322.

Hulzebos HJ, Snieder H, van der Et J, et al. High-intensity interval training in an adolescent with cystic fibrosis: a physiological perspective. Physiother Theory Pract 2011; 27: 231-237.

Santan Sosa E, Groeneveld IF, Gonzalez-Saiz L, et al. Intrahospital weight and aerobic training in children with cystic fibrosis: a randomized controlled trial. Med Sci Sports Exerc 2012; 44: 2-11.

Ram FS, Robinson SM, Black PN. Effects of physical training in asthma: a systematic review. Br J Sports Med 2000; 34: 162-167.

Troosters T, Casaburi R, Gosselink R, et al. Pulmonary rehabilitation in chronic obstructive pulmonary disease. Am J Respir Crit Care Med 2005; 172: 19-38.

Orens JB, Becker FS, Lynch JP 3rd, et al. Cardiopulmonary exercise testing following allogeneic lung transplantation for different underlying disease states. Chest 1995; 107: 144-149.

Reinsma GD, ten Hacken NH, Grevink RG, et al. Limiting factors of exercise performance 1 year after lung transplantation. J Heart Lung Transplant 2006; 25: 1310-1316.

Dolmage TE, Waddell TK, Maltais F, et al. The influence of lung volume reduction surgery on exercise in patients with COPD. Eur Respir J 2004; 23: 269-274.

Elphick HE, Mallory G. Oxygen therapy for cystic fibrosis. Cochrane Database Syst Rev 2013; 7: CD003884. short-term benefit of ambulatory oxygen in COPD. Chest 2007; 131: 278-285.

Liesker JJ, Wijkstra PJ, Ten Hacken NH, et al. A systematic review of the effects of bronchodilators on exercise capacity in patients with COPD. Chest 2002; 121: 597-608.

Akkoca Yildiz O, Onen ZP, Demir G, et al. Is there any difference between effects of ipratropium bromide and formoterol on exercise capacity in moderate COPD patients? Tuberk Toraks 2006; 54: 105-113.

O'Donnell DE, Voduc N, Fitzpatrick M, et al. Effect of salmeterol on the ventilatory response to exercise in chronic obstructive pulmonary disease. Eur Respir J 2004; 24: 86-94.

Yoshimura K, Maekura R, Hiraga T, et al. Effects of tiotropium on sympathetic activation during exercise in stable chronic obstructive pulmonary disease patients. Int J Chron Obstruct Pulmon Dis 2012; 7: 109-117. Aguilaniu B. Impact of bronchodilator therapy on exercise tolerance in COPD. Int J Chron Obstruct Pulmon Dis 2010; 5: 57-71.

Arena R, Lavie CJ, Milani RV, et al. Cardiopulmonary exercise testing in patients with pulmonary arterial hypertension: an evidence-based review. J Heart Lung Transplant 2010; 29: 159-173.

Johnson MK, Thompson S. The role of exercise testing in the modern management of pulmonary arterial hypertension. Diseases 2014; 2: 120-147. 
Barst RJ, McGoon M, McLaughlin V, et al. Beraprost therapy for pulmonary arterial hypertension. J Am Coll Cardiol 2003; 41: 2119-2125.

68 Harris-Eze AO, Sridhar G, Clemens RE, et al. Oxygen improves maximal exercise performance in interstitial lung disease. Am J Respir Crit Care Med 1994; 150: 1616-1622.

69 Maltais F, Simon M, Jobin J, et al. Effects of oxygen on lower limb blood flow and $\mathrm{O}_{2}$ uptake during exercise in COPD. Med Sci Sports Exerc 2001; 33: 916-922.

70 Kent L, O'Neill B, Davison G, et al. Cycle ergometer tests in children with cystic fibrosis: reliability and feasibility. Pediatr Pulmonol 2012; 47: 1226-1234.

71 Moorcroft AJ, Dodd ME, Webb AK. Exercise testing and prognosis in adult cystic fibrosis. Thorax 1997; 52: 291-293.

72 Lacasse Y, Goldstein R, Lasserson TJ, et al. Pulmonary rehabilitation for chronic obstructive pulmonary disease. Cochrane Database Syst Rev 2006; 4: CD003793.

73 McCarthy B, Casey D, Devane D, et al. Pulmonary rehabilitation for chronic obstructive pulmonary disease. Cochrane Database Syst Rev 2015; 2: CD003793.

74 Beauchamp MK, Nonoyama M, Goldstein RS, et al. Interval versus continuous training in individuals with chronic obstructive pulmonary disease - a systematic review. Thorax 2010; 65: 157-164.

75 Pouwels-Fry S, Pouwels S, Fournier C, et al. Effects of oxygen on exercise-induced increase of pulmonary arterial pressure in idiopathic pulmonary fibrosis. Sarcoidosis Vasc Diffuse Lung Dis 2008; 25: 133-139.

76 Sun XG, Hansen JE, Garatachea N, et al. Ventilatory efficiency during exercise in healthy subjects. Am J Respir Crit Care Med 2002; 166: 1443-1448.

77 Groepenhoff H, Vonk-Noordegraaf A, van de Veerdonk MC, et al. Prognostic relevance of changes in exercise test variables in pulmonary arterial hypertension. PLoS One 2013; 8: e72013.

78 Reybrouck T, Mertens L, Schulze-Neick I, et al. Ventilatory inefficiency for carbon dioxide during exercise in patients with pulmonary hypertension. Clin Physiol 1998; 18: 337-344.

79 Sun XG, Hansen JE, Oudiz RJ, et al. Gas exchange detection of exercise-induced right-to-left shunt in patients with primary pulmonary hypertension. Circulation 2002; 105: 54-60.

80 Paoletti P, De Filippis F, Fraioli F, et al. Cardiopulmonary exercise testing (CPET) in pulmonary emphysema. Respir Physiol Neurobiol 2011; 179: 167-173.

81 Davis JA, Sorrentino KM, Ninness EM, et al. Test-retest reliability for two indices of ventilatory efficiency measured during cardiopulmonary exercise testing in healthy men and women. Clin Physiol Funct Imaging 2006; 26: 191-196.

82 Keteyian SJ, Brawner CA, Ehrman JK, et al. Reproducibility of peak oxygen uptake and other cardiopulmonary exercise parameters: implications for clinical trials and clinical practice. Chest 2010; 138: 950-955.

83 Schwade J, Blomqvist CG, Shapiro W. A comparison of the response to arm and leg work in patients with ischemic heart disease. Am Heart J 1977; 94: 203-208.

84 Yasunobu Y, Oudiz RJ, Sun XG, et al. End-tidal $\mathrm{PCO}_{2}$ abnormality and exercise limitation in patients with primary pulmonary hypertension. Chest 2005; 127: 1637-1646.

85 Holverda S, Bogaard HJ, Groepenhoff H, et al. Cardiopulmonary exercise test characteristics in patients with chronic obstructive pulmonary disease and associated pulmonary hypertension. Respiration 2008; 76: $160-167$.

86 Gläser S, Obst A, Koch B, et al. Pulmonary hypertension in patients with idiopathic pulmonary fibrosis - the predictive value of exercise capacity and gas exchange efficiency. PLoS One 2013; 8: e65643.

87 Iwase T, Nagaya N, Ando M, et al. Acute and chronic effects of surgical thromboendarterectomy on exercise capacity and ventilatory efficiency in patients with chronic thromboembolic pulmonary hypertension. Heart 2001; 86: 188-192.

88 Theodore J, Robin ED, Morris AJ, et al. Augmented ventilatory response to exercise in pulmonary hypertension. Chest 1986; 89: 39-44.

89 Oudiz RJ, Roveran G, Hansen JE, et al. Effect of sildenafil on ventilatory efficiency and exercise tolerance in pulmonary hypertension. Eur J Heart Fail 2007; 9: 917-921.

90 Wensel R, Opitz CF, Ewert R, et al. Effects of iloprost inhalation on exercise capacity and ventilatory efficiency in patients with primary pulmonary hypertension. Circulation 2000; 101: 2388-2392.

91 Wax D, Garofano R, Barst RJ. Effects of long-term infusion of prostacyclin on exercise performance in patients with primary pulmonary hypertension. Chest 1999; 116: 914-920.

92 Ting $\mathrm{H}$, Sun XG, Chuang ML, et al. A noninvasive assessment of pulmonary perfusion abnormality in patients with primary pulmonary hypertension. Chest 2001; 119: 824-832.

93 Yang-Ting S, Aboulhosn J, Sun XG, et al. Effects of pulmonary vasodilator therapy on ventilatory efficiency during exercise in adults with Eisenmenger syndrome. Congenit Heart Dis 2011; 6: 139-146.

94 Nagaya N, Shimizu Y, Satoh T, et al. Oral beraprost sodium improves exercise capacity and ventilatory efficiency in patients with primary or thromboembolic pulmonary hypertension. Heart 2002; 87: 340-345.

95 Riley MS, Pórszász J, Engelen MP, et al. Responses to constant work rate bicycle ergometry exercise in primary pulmonary hypertension: the effect of inhaled nitric oxide. J Am Coll Cardiol 2000; 36: 547-556.

96 Miki K, Maekura R, Nagaya N, et al. Effects of ghrelin treatment on exercise capacity in underweight COPD patients: a substudy of a multicenter, randomized, double-blind, placebo-controlled trial of ghrelin treatment. BMC Pulm Med 2013; 13: 37.

97 Cooper CB, Abrazado M, Legg D, et al. Development and implementation of treadmill exercise testing protocols in COPD. Int J Chron Obstruct Pulmon Dis 2010; 5: 375-385.

98 Casaburi R, Patessio A, Ioli F, et al. Reductions in exercise lactic acidosis and ventilation as a result of exercise training in patients with obstructive lung disease. Am Rev Respir Dis 1991; 143: 9-18.

99 O'Donnell DE, Flüge T, Gerken F, et al. Effects of tiotropium on lung hyperinflation, dyspnoea and exercise tolerance in COPD. Eur Respir J 2004; 23: 832-840.

100 O'Donnell DE, Sciurba F, Celli B, et al. Effect of fluticasone propionate/salmeterol on lung hyperinflation and exercise endurance in COPD. Chest 2006; 130: 647-656.

101 O'Donnell DE, Casaburi R, Vincken W, et al. Effect of indacaterol on exercise endurance and lung hyperinflation in COPD. Respir Med 2011; 105: 1030-1036.

102 Puente-Maestu L, Villar F, de Miguel J, et al. Clinical relevance of constant power exercise duration changes in COPD. Eur Respir J 2009; 34: 340-345. 
103 Maltais F, Hamilton A, Marciniuk D, et al. Improvements in symptom-limited exercise performance over $8 \mathrm{~h}$ with once-daily tiotropium in patients with COPD. Chest 2005; 128: 1168-1178.

104 Maltais F, Celli B, Casaburi R, et al. Aclidinium bromide improves exercise endurance and lung hyperinflation in patients with moderate to severe COPD. Respir Med 2011; 105: 580-587.

105 van der Vaart H, Murgatroyd SR, Rossiter HB, et al. Selecting constant work rates for endurance testing in COPD: the role of the power-duration relationship. COPD 2014; 11: 267-276.

van 't Hul AJ, Gosselink R, Kwakkel G. Constant-load cycle endurance performance: test-retest reliability and validity in patients with COPD. J Cardiopulm Rehabil 2003; 23: 143-150.

107 Whipp BJ, Ward SA. Quantifying intervention-related improvements in exercise tolerance. Eur Respir J 2009; 33: $1254-1260$.

108 Andrianopoulos V, Wagers SS, Groenen MT, et al. Characteristics and determinants of endurance cycle ergometry and six-minute walk distance in patients with COPD. BMC Pulm Med 2014; 14: 97.

109 Vivodtzev I, Gagnon P, Pepin V, et al. Physiological correlates of endurance time variability during constant-workrate cycling exercise in patients with COPD. PLoS One 2011; 6: e17007.

110 Neder JA, Jones PW, Nery LE, et al. Determinants of the exercise endurance capacity in patients with chronic obstructive pulmonary disease. The power-duration relationship. Am J Respir Crit Care Med 2000; 162: 497-504.

111 Puente-Maestu L, Tena T, Trascasa C, et al. Training improves muscle oxidative capacity and oxygenation recovery kinetics in patients with chronic obstructive pulmonary disease. Eur J Appl Physiol 2003; 88: 580-587.

112 Rossiter HB. Exercise: kinetic considerations for gas exchange. Compr Physiol 2011; 1: 203-244.

113 Maltais F, LeBlanc P, Simard C, et al. Skeletal muscle adaptation to endurance training in patients with chronic obstructive pulmonary disease. Am J Respir Crit Care Med 1996; 154: 442-447.

114 Porszasz J, Emtner M, Goto S, et al. Exercise training decreases ventilatory requirements and exercise-induced hyperinflation at submaximal intensities in patients with COPD. Chest 2005; 128: 2025-2034.

115 Puente-Maestu L, Abad YM, Pedraza F, et al. A controlled trial of the effects of leg training on breathing pattern and dynamic hyperinflation in severe COPD. Lung 2006; 184: 159-167.

116 O'Donnell DE. Hyperinflation, dyspnea, and exercise intolerance in chronic obstructive pulmonary disease. Proc Am Thorac Soc 2006; 3: 180-184.

117 Berton DC, Barbosa PB, Takara LS, et al. Bronchodilators accelerate the dynamics of muscle $\mathrm{O}_{2}$ delivery and utilisation during exercise in COPD. Thorax 2010; 65: 588-593.

118 Beeh KM, Watz H, Puente-Maestu L, et al. Aclidinium improves exercise endurance, dyspnea, lung hyperinflation, and physical activity in patients with COPD: a randomized, placebo-controlled, crossover trial. BMC Pulm Med 2014; 14: 209.

119 Laviolette L, Bourbeau J, Bernard S, et al. Assessing the impact of pulmonary rehabilitation on functional status in COPD. Thorax 2008; 63: 115-121.

120 Hopkinson NS, Toma TP, Hansell DM, et al. Effect of bronchoscopic lung volume reduction on dynamic hyperinflation and exercise in emphysema. Am J Respir Crit Care Med 2005; 171: 453-460.

121 de Man FS, Handoko ML, Groepenhoff $\mathrm{H}$, et al. Effects of exercise training in patients with idiopathic pulmonary arterial hypertension. Eur Respir J 2009; 34: 669-675.

122 Mainguy V, Maltais F, Saey D, et al. Effects of a rehabilitation program on skeletal muscle function in idiopathic pulmonary arterial hypertension. J Cardiopulm Rehabil Prev 2010; 30: 319-323.

123 Arizono S, Taniguchi H, Sakamoto $\mathrm{K}$, et al. Endurance time is the most responsive exercise measurement in idiopathic pulmonary fibrosis. Respir Care 2014; 59: 1108-1115.

124 Jackson RM, Gómez-Marín OW, Ramos CF, et al. Exercise limitation in IPF patients: a randomized trial of pulmonary rehabilitation. Lung 2014; 192: 367-376.

125 Holland AE. Exercise limitation in interstitial lung disease - mechanisms, significance and therapeutic options. Chron Respir Dis 2010; 7: 101-111.

126 Borghi-Silva A, Oliveira CC, Carrascosa C, et al. Respiratory muscle unloading improves leg muscle oxygenation during exercise in patients with COPD. Thorax 2008; 63: 910-915.

127 Beeh KM, Wagner F, Khindri S, et al. Effect of indacaterol on dynamic lung hyperinflation and breathlessness in hyperinflated patients with COPD. COPD 2011; 8: 340-345.

128 Bradley JM, Lasserson T, Elborn S, et al. A systematic review of randomized controlled trials examining the short-term benefit of ambulatory oxygen in COPD. Chest 2007; 131: 278-285.

129 Emtner M, Porszasz J, Burns M, et al. Benefits of supplemental oxygen in exercise training in nonhypoxemic chronic obstructive pulmonary disease patients. Am J Respir Crit Care Med 2003; 168: 1034-1042.

130 Palange $\mathrm{P}$, Valli G, Onorati $\mathrm{P}$, et al. Effect of heliox on lung dynamic hyperinflation, dyspnea, and exercise endurance capacity in COPD patients. J Appl Physiol 2004; 97: 1637-1642.

131 Puente-Maestu L, Sánz ML, Sánz P, et al. Effects of two types of training on pulmonary and cardiac responses to moderate exercise in patients with COPD. Eur Respir J 2000; 15: 1026-1032.

132 Henke KG, Regnis JA, Bye PT. Benefits of continuous positive airway pressure during exercise in cystic fibrosis and relationship to disease severity. Am Rev Respir Dis 1993; 148: 1272-1276.

133 Lee WT, Brown A, Peacock AJ, et al. Use of non-invasive haemodynamic measurements to detect treatment response in precapillary pulmonary hypertension. Thorax 2011; 66: 810-814.

134 Epstein SK, Celli BR, Martinez FJ, et al. Arm training reduces the $V^{\prime} \mathrm{O}_{2}$ and $V^{\prime} \mathrm{E}$ cost of unsupported arm exercise and elevation in chronic obstructive pulmonary disease. J Cardiopulm Rehabil 1997; 17: 171-177.

135 Menadue C, Alison JA, Piper AJ, et al. Non-invasive ventilation during arm exercise and ground walking in patients with chronic hypercapnic respiratory failure. Respirology 2009; 14: 251-259.

136 Romagnoli I, Scano G, Binazzi B, et al. Effects of unsupported arm training on arm exercise-related perception in COPD patients. Respir Physiol Neurobiol 2013; 186: 95-102.

137 Younes M. Determinants of thoracic excursions. In: Whipp BJ, Wasserman K, eds. Pulmonary Physiology and Pathophysiology of Exercise. New York, Dekker, 1991; pp. 1-65.

138 Dolmage TE, Goldstein RS. Repeatability of inspiratory capacity during incremental exercise in patients with severe COPD. Chest 2002; 121: 708-714.

139 Guenette JA, Chin RC, Cory JM, et al. Inspiratory capacity during exercise: measurement, analysis, and interpretation. Pulm Med 2013; 2013: 956081. 

changes during exercise in patients with chronic obstructive pulmonary disease. Am J Respir Crit Care Med 1997; 156: 55-59.

141 O'Donnell DE, Laveneziana P. Dyspnea and activity limitation in COPD: mechanical factors. COPD 2007; 4: 225-236.

142 Newton MF, O’Donnell DE, Forkert L. Response of lung volumes to inhaled salbutamol in a large population of patients with severe hyperinflation. Chest 2002; 121: 1042-1050.

143 O'Donnell DE, Forkert L, Webb KA. Evaluation of bronchodilator responses in patients with "irreversible" emphysema. Eur Respir J 2001; 18: 914-920.

144 Díaz O, Villafranca C, Ghezzo H, et al. Breathing pattern and gas exchange at peak exercise in COPD patients with and without tidal flow limitation at rest. Eur Respir J 2001; 17: 1120-1127.

145 Puente-Maestu L, García de Pedro J, Martínez-Abad Y, et al. Dyspnea, ventilatory pattern, and changes in dynamic hyperinflation related to the intensity of constant work rate exercise in COPD. Chest 2005; 128: 651-656.

146 Garcia-Rio F, Lores V, Mediano O, et al. Daily physical activity in patients with chronic obstructive pulmonary disease is mainly associated with dynamic hyperinflation. Am J Respir Crit Care Med 2009; 180: 506-512.

147 O'Donnell DE, Lam M, Webb KA. Measurement of symptoms, lung hyperinflation, and endurance during exercise in chronic obstructive pulmonary disease. Am J Respir Crit Care Med 1998; 158: 1557-1565.

148 Ozgür ES, Nayci SA, Özge C, et al. An integrated index combined by dynamic hyperinflation and exercise capacity in the prediction of morbidity and mortality in COPD. Respir Care 2012; 57: 1452-1459.

149 Vogiatzis I, Stratakos G, Athanasopoulos D, et al. Chest wall volume regulation during exercise in COPD patients with GOLD stages II to IV. Eur Respir J 2008; 32: 42-52.

150 O'Donnell DE, Revill SM, Webb KA. Dynamic hyperinflation and exercise intolerance in chronic obstructive pulmonary disease. Am J Respir Crit Care Med 2001; 164: 770-777.

151 de Jong W, van der Schans CP, Mannes GP, et al. Relationship between dyspnoea, pulmonary function and exercise capacity in patients with cystic fibrosis. Respir Med 1997; 91: 41-46.

152 Hajiro T, Nishimura K, Tsukino M, et al. Analysis of clinical methods used to evaluate dyspnea in patients with chronic obstructive pulmonary disease. Am J Respir Crit Care Med 1998; 158: 1185-1189.

153 Borg GA. Psychophysical bases of perceived exertion. Med Sci Sports Exerc 1982; 14: 377-381.

154 Cazzola M, MacNee W, Martinez FJ, et al. Outcomes for COPD pharmacological trials: from lung function to biomarkers. Eur Respir J 2008; 31: 416-469.

155 Hareendran A, Leidy NK, Monz BU, et al. Proposing a standardized method for evaluating patient report of the intensity of dyspnea during exercise testing in COPD. Int J Chron Obstruct Pulmon Dis 2012; 7: 345-355.

156 Mahler DA, O’Donnell DE. Recent advances in dyspnea. Chest 2015; 147: 232-241.

157 Hamilton AL, Killian KJ, Summers E, et al. Symptom intensity and subjective limitation to exercise in patients with cardiorespiratory disorders. Chest 1996; 110: 1255-1263.

158 Franco MJ, Olmstead EM, Tosteson AN, et al. Comparison of dyspnea ratings during submaximal constant work exercise with incremental testing. Med Sci Sports Exerc 1998; 30: 479-482.

159 O'Donnell DE, Laveneziana P, Ora J, et al. Evaluation of acute bronchodilator reversibility in patients with symptoms of GOLD stage I COPD. Thorax 2009; 64: 216-223.

160 Swigris JJ, Streiner DL, Brown KK, et al. Assessing exertional dyspnea in patients with idiopathic pulmonary fibrosis. Respir Med 2014; 108: 181-188.

161 Wilson RC, Jones PW. Long-term reproducibility of Borg scale estimates of breathlessness during exercise. Clin Sci (Lond) 1991; 80: 309-312.

162 Oga T, Tsukino M, Hajiro T, et al. Analysis of longitudinal changes in dyspnea of patients with chronic obstructive pulmonary disease: an observational study. Respir Res 2012; 13: 85.

163 Ries AL. Minimally clinically important difference for the UCSD Shortness of Breath Questionnaire, Borg Scale, and Visual Analog Scale. COPD 2005; 2: 105-110.

164 Uronis HE, Ekström MP, Currow DC, et al. Oxygen for relief of dyspnoea in people with chronic obstructive pulmonary disease who would not qualify for home oxygen: a systematic review and meta-analysis. Thorax 2015; 70: 492-494.

165 Visca D, Montgomery A, de Lauretis A, et al. Ambulatory oxygen in interstitial lung disease. Eur Respir J 2011; 38: 987-990.

166 Nishiyama O, Miyajima H, Fukai Y, et al. Effect of ambulatory oxygen on exertional dyspnea in IPF patients without resting hypoxemia. Respir Med 2013; 107: 1241-1246.

167 Jenkins S, Čečins N. Six-minute walk test: observed adverse events and oxygen desaturation in a large cohort of patients with chronic lung disease. Intern Med J 2011; 41: 416-422.

168 Casas A, Vilaro J, Rabinovich R, et al. Encouraged 6-min walking test indicates maximum sustainable exercise in COPD patients. Chest 2005; 128: 55-61.

169 Holland AE, Dowman L, Fiore J Jr, et al. Cardiorespiratory responses to 6-minute walk test in interstitial lung disease: not always a submaximal test. BMC Pulm Med 2014; 14: 136.

170 Deboeck G, Niset G, Vachiery JL, et al. Physiological response to the six-minute walk test in pulmonary arterial hypertension. Eur Respir J 2005; 26: 667-672.

171 Hill K, Dolmage TE, Woon L, et al. Comparing peak and submaximal cardiorespiratory responses during field walking tests with incremental cycle ergometry in COPD. Respirology 2012; 17: 278-284.

172 Singh SJ, Puhan MA, Andrianopoulos V, et al. An official systematic review of the European Respiratory Society/ American Thoracic Society: measurement properties of field walking tests in chronic respiratory disease. Eur Respir J 2014; 44: 1447-1478.

173 Singh SJ, Morgan MD, Scott S, et al. Development of a shuttle walking test of disability in patients with chronic airways obstruction. Thorax 1992; 47: 1019-1024.

174 Pepin V, Saey D, Whittom F, et al. Walking versus cycling: sensitivity to bronchodilation in chronic obstructive pulmonary disease. Am J Respir Crit Care Med 2005; 172: 1517-1522.

175 Johnson-Warrington V, Williams J, Bankart J, et al. Pulmonary rehabilitation and interstitial lung disease: aiding the referral decision. J Cardiopulm Rehabil Prev 2013; 33: 189-195. 
Coelho CC, Aquino Eda S, de Almeida DC, et al. Comparative analysis and reproducibility of the modified shuttle walk test in normal children and in children with cystic fibrosis. J Bras Pneumol 2007; 33: 168-174.

Holland AE, Spruit MA, Troosters T, et al. An official European Respiratory Society/American Thoracic Society technical standard: field walking tests in chronic respiratory disease. Eur Respir J 2014; 44: 1428-1446.

Steiner MC, Singh SJ, Morgan MD. The contribution of peripheral muscle function to shuttle walking performance in patients with chronic obstructive pulmonary disease. J Cardiopulm Rehabil 2005; 25 : 43-49.

Dowson LJ, Newall C, Guest PJ, et al. Exercise capacity predicts health status in $\alpha_{1}$-antitrypsin deficiency. Am J Respir Crit Care Med 2001; 163: 936-941.

Dodd JW, Hogg L, Nolan J, et al. The COPD assessment test (CAT): response to pulmonary rehabilitation. A multicentre, prospective study. Thorax 2011; 66: 425-429.

Dyer F, Marriner P, Cheema K, et al. Is a practice incremental shuttle walk test really necessary? Chron Respir Dis 2011; 8: 201-205.

Emtner MI, Arnardottir HR, Hallin R, et al. Walking distance is a predictor of exacerbations in patients with chronic obstructive pulmonary disease. Respir Med 2007; 101: 1037-1040.

Ringbaek T, Martinez G, Brøndum E, et al. Shuttle walking test as predictor of survival in chronic obstructive pulmonary disease patients enrolled in a rehabilitation program. J Cardiopulm Rehabil Prev 2010; 30: 409-414. Singh SJ, Jones PW, Evans R, et al. Minimum clinically important improvement for the incremental shuttle walking test. Thorax 2008; 63: 775-777.

Puhan MA, Gimeno-Santos E, Scharplatz M, et al. Pulmonary rehabilitation following exacerbations of chronic obstructive pulmonary disease. Cochrane Database Syst Rev 2011; 10: CD005305.

Garrod R, Paul EA, Wedzicha JA. Supplemental oxygen during pulmonary rehabilitation in patients with COPD with exercise hypoxaemia. Thorax 2000; 55: 539-543.

Sandland CJ, Morgan MD, Singh SJ. Detecting oxygen desaturation in patients with COPD: incremental versus endurance shuttle walking. Respir Med 2008; 102: 1148-1152.

Deschênes D, Pepin V, Saey D, et al. Locus of symptom limitation and exercise response to bronchodilation in chronic obstructive pulmonary disease. J Cardiopulm Rehabil Prev 2008; 28: 208-214.

Dyer CA, Singh SJ, Stockley RA, et al. The incremental shuttle walking test in elderly people with chronic airflow limitation. Thorax 2002; 57: 34-38.

Verkindre C, Bart F, Aguilaniu B, et al. The effect of tiotropium on hyperinflation and exercise capacity in chronic obstructive pulmonary disease. Respiration 2006; 73: 420-427.

Aalbers R, Ayres J, Backer V, et al. Formoterol in patients with chronic obstructive pulmonary disease: a randomized, controlled, 3-month trial. Eur Respir J 2002; 19: 936-943.

Murray MP, Turnbull K, Macquarrie S, et al. Assessing response to treatment of exacerbations of bronchiectasis in adults. Eur Respir J 2009; 33: 312-318.

Revill SM, Morgan MD, Singh SJ, et al. The endurance shuttle walk: a new field test for the assessment of endurance capacity in chronic obstructive pulmonary disease. Thorax 1999; 54: 213-222. bronchodilation in COPD. Eur Respir J 2014; 44: 1166-1146.

Bedard ME, Brouillard C, Pepin V, et al. Tiotropium improves walking endurance in COPD. Eur Respir J 2012; 39: $265-271$.

Brouillard C, Pepin V, Milot J, et al. Endurance shuttle walking test: responsiveness to salmeterol in COPD. Eur Respir J 2008; 31: 579-584.

Pepin V, Brodeur J, Lacasse Y, et al. Six-minute walking versus shuttle walking: responsiveness to bronchodilation in chronic obstructive pulmonary disease. Thorax 2007; 62: 291-298.

Maltais F, Singh S, Donald AC, et al. Effects of a combination of umeclidinium/vilanterol on exercise endurance in patients with chronic obstructive pulmonary disease: two randomized, double-blind clinical trials. Ther Adv Respir Dis 2014; 8: 169-181.

Witham MD, Sugden JA, Sumukadas D, et al. A comparison of the Endurance Shuttle Walk test and the Six Minute Walk test for assessment of exercise capacity in older people. Aging Clin Exp Res 2012; 24: 176-180.

Maltais F, Mahler DA, Pepin V, et al. Effect of fluticasone propionate/salmeterol plus tiotropium versus tiotropium on walking endurance in COPD. Eur Respir J 2013; 42: 539-541.

Revill SM, Williams J, Sewell L, et al. Within-day repeatability of the endurance shuttle walk test. Physiotherapy 2009; 95: 140-143.

McKeough ZJ, Leung RW, Alison JA. Shuttle walk tests as outcome measures: are two incremental shuttle walk tests and two endurance shuttle walk tests necessary? Am J Phys Med Rehabil 2011; 90: 35-39.

Mandal P, Sidhu MK, Kope L, et al. A pilot study of pulmonary rehabilitation and chest physiotherapy versus chest physiotherapy alone in bronchiectasis. Respir Med 2012; 106: 1647-1654.

Revill SM, Singh SJ, Morgan MD. Randomized controlled trial of ambulatory oxygen and an ambulatory ventilator on endurance exercise in COPD. Respir Med 2000; 94: 778-783.

Gagnon P, Saey D, Provencher S, et al. Walking exercise response to bronchodilation in mild COPD: a randomized trial. Respir Med 2012; 106: 1695-1705.

Mainguy V, Malenfant S, Neyron AS, et al. Repeatability and responsiveness of exercise tests in pulmonary arterial hypertension. Eur Respir J 2013; 42: 425-434.

Butland RJ, Pang J, Gross ER, et al. Two-, six-, and 12-minute walking tests in respiratory disease. $\mathrm{Br} \mathrm{Med} J(\mathrm{Clin}$ Res Ed) 1982; 284: 1607-1608.

8 Beekman E, Mesters I, Hendriks EJ, et al. Course length of 30 metres versus 10 metres has a significant influence on six-minute walk distance in patients with COPD: an experimental crossover study. J Physiother 2013; 59: $169-176$.

Eiser N, Willsher D, Doré CJ. Reliability, repeatability and sensitivity to change of externally and self-paced walking tests in COPD patients. Respir Med 2003; 97: 407-414.

Hernandes NA, Wouters EF, Meijer K, et al. Reproducibility of 6-minute walking test in patients with COPD. Eur Respir J 2011; 38: 261-267.

Eaton T, Young P, Milne D, et al. Six-minute walk, maximal exercise tests: reproducibility in fibrotic interstitial pneumonia. Am J Respir Crit Care Med 2005; 171: 1150-1157. 
212 Miyamoto S, Nagaya N, Satoh T, et al. Clinical correlates and prognostic significance of six-minute walk test in patients with primary pulmonary hypertension. Comparison with cardiopulmonary exercise testing. Am J Respir Crit Care Med 2000; 161: 487-492.

213 Oga T, Nishimura K, Tsukino M, et al. Relationship between different indices of exercise capacity and clinical measures in patients with chronic obstructive pulmonary disease. Heart Lung 2002; 31: 374-381.

214 Sillen MJ, Vercoulen $\mathrm{JH}$, van 't Hul AJ, et al. Inaccuracy of estimating peak work rate from six-minute walk distance in patients with COPD. COPD 2012; 9: 281-288.

215 Wijkstra PJ, TenVergert EM, van der Mark TW, et al. Relation of lung function, maximal inspiratory pressure, dyspnoea, and quality of life with exercise capacity in patients with chronic obstructive pulmonary disease. Thorax 1994; 49: 468-472.

216 Brown CD, Benditt JO, Sciurba FC, et al. Exercise testing in severe emphysema: association with quality of life and lung function. COPD 2008; 5: 117-124.

217 Rejeski WJ, Foley KO, Woodard CM, et al. Evaluating and understanding performance testing in COPD patients. J Cardiopulm Rehabil 2000; 20: 79-88.

218 Doyle TJ, Washko GR, Fernandez IE, et al. Interstitial lung abnormalities and reduced exercise capacity. Am J Respir Crit Care Med 2012; 185: 756-762.

219 du Bois RM, Weycker D, Albera C, et al. Six-minute-walk test in idiopathic pulmonary fibrosis: test validation and minimal clinically important difference. Am J Respir Crit Care Med 2011; 183: 1231-1237.

Chua R, Keogh AM, Byth K, et al. Comparison and validation of three measures of quality of life in patients with pulmonary hypertension. Intern Med J 2006; 36: 705-710.

Savarese G, Musella F, D'Amore C, et al. Haemodynamics, exercise capacity and clinical events in pulmonary arterial hypertension. Eur Respir J 2013; 42: 414-424.

abler NB, French B, Strom BL, et al Validation of 6-minute walk distance as a surrogate end point in pulmonary arterial hypertension trials. Circulation 2012; 126: 349-356.

223 Hill K, Dolmage TE, Woon L, et al. Defining the relationship between average daily energy expenditure and field-based walking tests and aerobic reserve in COPD. Chest 2012; 141: 406-412.

224 Mainguy V, Provencher S, Maltais F, et al. Assessment of daily life physical activities in pulmonary arterial hypertension. PLoS One 2011; 6: e27993.

225 Pitta F, Troosters T, Spruit MA, et al. Characteristics of physical activities in daily life in chronic obstructive pulmonary disease. Am J Respir Crit Care Med 2005; 171: 972-977.

226 Poulain M, Durand F, Palomba B, et al. 6-minute walk testing is more sensitive than maximal incremental cycle testing for detecting oxygen desaturation in patients with COPD. Chest 2003; 123: 1401-1407. Respir Res 2010; 11: 122.

228 Noble PW, Albera C, Bradford WZ, et al. Pirfenidone in patients with idiopathic pulmonary fibrosis (CAPACITY): two randomised trials. Lancet 2011; 377: 1760-1769.

229 Frost AE, Langleben D, Oudiz R, et al. The 6-min walk test (6MW) as an efficacy endpoint in pulmonary arterial hypertension clinical trials: demonstration of a ceiling effect. Vascul Pharmacol 2005; 43: 36-39.

230 Lipkin DP, Scriven AJ, Crake T, et al. Six minute walking test for assessing exercise capacity in chronic heart failure. Br Med J (Clin Res Ed) 1986; 292: 653-655.

231 Holland AE, Hill CJ, Glaspole I, et al. Impaired chronotropic response to 6-min walk test and reduced survival in interstitial lung disease. Respir Med 2013; 107: 1066-1072.

232 Lettieri CJ, Nathan SD, Browning RF, et al. The distance-saturation product predicts mortality in idiopathic pulmonary fibrosis. Respir Med 2006; 100: 1734-1741.

233 Minai OA, Gudavalli R, Mummadi S, et al. Heart rate recovery predicts clinical worsening in patients with pulmonary arterial hypertension. Am J Respir Crit Care Med 2012; 185: 400-408.

234 Spruit MA, Polkey MI, Celli B, et al. Predicting outcomes from 6-minute walk distance in chronic obstructive pulmonary disease. J Am Med Dir Assoc 2012; 13: 291-297.

235 Cote CG, Pinto-Plata V, Kasprzyk K, et al. The 6-min walk distance, peak oxygen uptake, and mortality in COPD. Chest 2007; 132: 1778-1785.

236 Sitbon $\mathrm{O}$, Humbert $\mathrm{M}$, Nunes $\mathrm{H}$, et al. Long-term intravenous epoprostenol infusion in primary pulmonary hypertension: prognostic factors and survival. J Am Coll Cardiol 2002; 40: 780-788.

237 Benza RL, Miller DP, Gomberg-Maitland M, et al. Predicting survival in pulmonary arterial hypertension: insights from the Registry to Evaluate Early and Long-Term Pulmonary Arterial Hypertension Disease Management (REVEAL). Circulation 2010; 122: 164-172.

238 Lacasse Y, Wong E, Guyatt GH, et al. Meta-analysis of respiratory rehabilitation in chronic obstructive pulmonary disease. Lancet 1996; 348: 1115-1119.

239 Weiner P, Magadle R, Berar-Yanay N, et al. The cumulative effect of long-acting bronchodilators, exercise, and inspiratory muscle training on the perception of dyspnea in patients with advanced COPD. Chest 2000; 118: 672-678.

240 Criner GJ, Cordova FC, Furukawa S, et al. Prospective randomized trial comparing bilateral lung volume reduction surgery to pulmonary rehabilitation in severe chronic obstructive pulmonary disease. Am J Respir Crit Care Med 1999; 160: 2018-2027.

241 Leach RM, Davidson AC, Chinn S, et al. Portable liquid oxygen and exercise ability in severe respiratory disability. Thorax 1992; 47: 781-789.

242 Holland A, Hill C. Physical training for interstitial lung disease. Cochrane Database Syst Rev 2008; 4: CD006322.

243 Fox BD, Kassirer M, Weiss I, et al. Ambulatory rehabilitation improves exercise capacity in patients with pulmonary hypertension. J Card Fail 2011; 17: 196-200.

244 Mereles D, Ehlken N, Kreuscher S, et al. Exercise and respiratory training improve exercise capacity and quality of life in patients with severe chronic pulmonary hypertension. Circulation 2006; 114: 1482-1489.

245 Frank RC, Hicks S, Duck AM, et al. Ambulatory oxygen in idiopathic pulmonary fibrosis: of what benefit? Eur Respir J 2012; 40: 269-270. 
Satake M, Takahashi H, Sugawara K, et al. Inhibitory effect of procaterol on exercise dynamic lung hyperinflation during the 6-min walk test in stable patients with chronic obstructive pulmonary disease. Arzneimittelforschung 2011; 61: 8-13.

Oga T, Nishimura K, Tsukino M, et al. The effects of oxitropium bromide on exercise performance in patients with stable chronic obstructive pulmonary disease. A comparison of three different exercise tests. Am J Respir Crit Care Med 2000; 161: 1897-1901.

Boyd G, Morice AH, Pounsford JC, et al. An evaluation of salmeterol in the treatment of chronic obstructive pulmonary disease (COPD). Eur Respir J 1997; 10: 815-821.

Cazzola M, Biscione GL, Pasqua F, et al. Use of 6-min and 12-min walking test for assessing the efficacy of formoterol in COPD. Respir Med 2008; 102: 1425-1430.

Okudan N, Gök M, Gökbel H, et al. Single dose of tiotropium improves the 6-minute walk distance in chronic obstructive pulmonary disease. Lung 2006; 184: 201-204.

Macchia A, Marchioli R, Tognoni G, et al. Systematic review of trials using vasodilators in pulmonary arterial hypertension: why a new approach is needed. Am Heart J 2010; 159: 245-257.

recovery in patients with COPD. COPD 2014; 11: 190-196.

Blanco I, Santos S, Gea J, et al. Sildenafil to improve respiratory rehabilitation outcomes in COPD: a controlled trial. Eur Respir J 2013; 42: 982-992.

van 't Hul A, Gosselink R, Hollander P, et al. Training with inspiratory pressure support in patients with severe COPD. Eur Respir J 2006; 27: 65-72.

Ong KC, Chong WF, Soh C, et al. Comparison of different exercise tests in assessing outcomes of pulmonary rehabilitation. Respir Care 2004; 49: 1498-1503.

Hawkins P, Johnson LC, Nikoletou D, et al. Proportional assist ventilation as an aid to exercise training in severe chronic obstructive pulmonary disease. Thorax 2002; 57: 853-859.

O’Donnell DE, McGuire M, Samis L, et al. General exercise training improves ventilatory and peripheral muscle strength and endurance in chronic airflow limitation. Am J Respir Crit Care Med 1998; 157: 1489-1497.

Cambach W, Chadwick-Straver RV, Wagenaar RC, et al. The effects of a community-based pulmonary rehabilitation programme on exercise tolerance and quality of life: a randomized controlled trial. Eur Respir $J$ 1997; 10: 104-113.

Louvaris Z, Vogiatzis I, Aliverti A, et al. Blood flow does not redistribute from respiratory to leg muscles during exercise breathing heliox or oxygen in COPD. J Appl Physiol 2014; 117: 267-276.

Vogiatzis I, Louvaris Z, Habazettl H, et al. Cerebral cortex oxygen delivery and exercise limitation in patients with COPD. Eur Respir J 2013; 41: 295-301.

Louvaris Z, Zakynthinos S, Aliverti A, et al. Heliox increases quadriceps muscle oxygen delivery during exercise in COPD patients with and without dynamic hyperinflation. J Appl Physiol 2012; 113: 1012-1023.

Laveneziana P, Valli G, Onorati P, et al. Effect of heliox on heart rate kinetics and dynamic hyperinflation during high-intensity exercise in COPD. Eur J Appl Physiol 2011; 111: 225-234.

Scorsone D, Bartolini S, Saporiti R, et al. Does a low-density gas mixture or oxygen supplementation improve exercise training in COPD? Chest 2010; 138: 1133-1139.

Chiappa GR, Queiroga F Jr, Meda E, et al. Heliox improves oxygen delivery and utilization during dynamic exercise in patients with chronic obstructive pulmonary disease. Am J Respir Crit Care Med 2009; 179: 1004-1010.

Butcher SJ, Lagerquist O, Marciniuk DD, et al. Relationship between ventilatory constraint and muscle fatigue during exercise in COPD. Eur Respir J 2009; 33: 763-770.

Eves ND, Petersen SR, Haykowsky MJ, et al. Helium-hyperoxia, exercise, and respiratory mechanics in chronic obstructive pulmonary disease. Am J Respir Crit Care Med 2006; 174: 763-771.

Porszasz J, Cao R, Morishige R, et al. Physiologic effects of an ambulatory ventilation system in chronic obstructive pulmonary disease. Am J Respir Crit Care Med 2013; 188: 334-342.

Siqueira AC, Borghi-Silva A, Bravo DM, et al. Effects of hyperoxia on the dynamics of skeletal muscle oxygenation at the onset of heavy-intensity exercise in patients with COPD. Respir Physiol Neurobiol 2010; 172 : 8-14.

Heraud N, Prefaut C, Durand F, et al. Does correction of exercise-induced desaturation by $\mathrm{O}_{2}$ always improve exercise tolerance in COPD? A preliminary study. Respir Med 2008; 102: 1276-1286.

O'Donnell DE, D'Arsigny C, Webb KA. Effects of hyperoxia on ventilatory limitation during exercise in advanced chronic obstructive pulmonary disease. Am J Respir Crit Care Med 2001; 163: 892-898.

Oliveira CC, Carrascosa CR, Borghi-Silva A, et al. Influence of respiratory pressure support on hemodynamics and exercise tolerance in patients with COPD. Eur J Appl Physiol 2010; 109: 681-689.

2 Carrascosa CR, Oliveira CC, Borghi-Silva A, et al. Haemodynamic effects of proportional assist ventilation during high-intensity exercise in patients with chronic obstructive pulmonary disease. Respirology 2010; 15: $1185-1191$.

Borghi-Silva A, Carrascosa C, Oliveira CC, et al. Effects of respiratory muscle unloading on leg muscle oxygenation and blood volume during high-intensity exercise in chronic heart failure. Am J Physiol Heart Circ Physiol 2008; 294: H2465-H2472.

4 van 't Hul A, Gosselink R, Hollander P, et al. Acute effects of inspiratory pressure support during exercise in patients with COPD. Eur Respir J 2004; 23: 34-40.

Hernandez P, Maltais F, Gursahaney A, et al. Proportional assist ventilation may improve exercise performance in severe chronic obstructive pulmonary disease. J Cardiopulm Rehabil 2001; 21: 135-142.

Bianchi L, Foglio K, Pagani M, et al. Effects of proportional assist ventilation on exercise tolerance in COPD patients with chronic hypercapnia. Eur Respir J 1998; 11: 422-427.

Dolmage TE, Goldstein RS. Proportional assist ventilation and exercise tolerance in subjects with COPD. Chest 1997; 111: 948-954.

Aliverti A, Rodger K, Dellacà RL, et al. Effect of salbutamol on lung function and chest wall volumes at rest and during exercise in COPD. Thorax 2005; 60: 916-924.

Oga T, Nishimura K, Tsukino M, et al. Exercise responses during endurance testing at different intensities in patients with COPD. Respir Med 2004; 98: 515-521. 
Oga T, Nishimura K, Tsukino M, et al. A comparison of the effects of salbutamol and ipratropium bromide on exercise endurance in patients with COPD. Chest 2003; 123: 1810-1816.

Saey D, Debigare R, LeBlanc P, et al. Contractile leg fatigue after cycle exercise: a factor limiting exercise in patients with chronic obstructive pulmonary disease. Am J Respir Crit Care Med 2003; 168: 425-430.

Scuarcialupi ME, Berton DC, Cordoni PK, et al. Can bronchodilators improve exercise tolerance in COPD patients without dynamic hyperinflation? J Bras Pneumol 2014; 40: 111-118.

Laveneziana P, Palange P, Ora J, et al. Bronchodilator effect on ventilatory, pulmonary gas exchange, and heart rate kinetics during high-intensity exercise in COPD. Eur J Appl Physiol 2009; 107: 633-643.

Canto ND, Ribeiro JP, Neder JA, et al. Addition of tiotropium to formoterol improves inspiratory muscle strength after exercise in COPD. Respir Med 2012; 106: 1404-1412.

van der Vaart H, Postma DS, Grevink R, et al. Bronchodilation improves endurance but not muscular efficiency in chronic obstructive pulmonary disease. Int J Chron Obstruct Pulmon Dis 2011; 6: 229-235.

Zhang W, Fievez L, Zhang F, et al. Effects of formoterol and ipratropium bromide on repeated cadmium inhalation-induced pulmonary inflammation and emphysema in rats. Eur J Pharmacol 2010; 647: 178-187.

Zhang X, Waterman LA, Ward J, et al. Advantages of endurance treadmill walking compared with cycling to assess bronchodilator therapy. Chest 2010; 137: 1354-1361.

Worth H, Förster K, Eriksson G, et al. Budesonide added to formoterol contributes to improved exercise tolerance in patients with COPD. Respir Med 2010; 104: 1450-1459.

Neder JA, Fuld JP, Overend T, et al. Effects of formoterol on exercise tolerance in severely disabled patients with COPD. Respir Med 2007; 101: 2056-2064.

Man WD, Mustfa N, Nikoletou D, et al. Effect of salmeterol on respiratory muscle activity during exercise in poorly reversible COPD. Thorax 2004; 59: 471-476.

Guenette JA, Webb KA, O'Donnell DE. Effect of fluticasone/salmeterol combination on dyspnea and respiratory mechanics in mild-to-moderate COPD. Respir Med 2013; 107: 708-716.

Magnussen H, Paggiaro P, Schmidt H, et al. Effect of combination treatment on lung volumes and exercise endurance time in COPD. Respir Med 2012; 106: 1413-1420.

Guenette JA, Raghavan N, Harris-McAllister V, et al. Effect of adjunct fluticasone propionate on airway physiology during rest and exercise in COPD. Respir Med 2011; 105: 1836-1845.

Cooper CB, Celli BR, Jardim JR, et al. Treadmill endurance during 2-year treatment with tiotropium in patients with COPD: a randomized trial. Chest 2013; 144: 490-497.

Yoshimura K, Maekura R, Hiraga T, et al. Effects of tiotropium on sympathetic activation during exercise in stable chronic obstructive pulmonary disease patients. Int J Chron Obstruct Pulmon Dis 2012; 7: 109-117.

Beeh KM, Singh D, Di Scala L, et al. Once-daily NVA237 improves exercise tolerance from the first dose in patients with COPD: the GLOW3 trial. Int J Chron Obstruct Pulmon Dis 2012; 7: 503-513.

Casaburi R, Kukafka D, Cooper CB, et al. Improvement in exercise tolerance with the combination of tiotropium and pulmonary rehabilitation in patients with COPD. Chest 2005; 127: 809-817.

Revitt O, Sewell L, Morgan MD, et al. Short outpatient pulmonary rehabilitation programme reduces readmission following a hospitalization for an exacerbation of chronic obstructive pulmonary disease. Respirology 2013; 18: 1063-1068.

Jones SE, Green SA, Clark AL, et al. Pulmonary rehabilitation following hospitalisation for acute exacerbation of COPD: referrals, uptake and adherence. Thorax 2014; 69: 181-182.

Dodd JW, Marns PL, Clark AL, et al. The COPD Assessment Test (CAT): short- and medium-term response to pulmonary rehabilitation. COPD 2012; 9: 390-394.

Seymour JM, Moore L, Jolley CJ, et al. Outpatient pulmonary rehabilitation following acute exacerbations of COPD. Thorax 2010; 65: 423-428.

Leung RW, Alison JA, McKeough ZJ, et al. Ground walk training improves functional exercise capacity more than cycle training in people with chronic obstructive pulmonary disease (COPD): a randomised trial. J Physiother 2010; 56: 105-112.

Moore J, Fiddler H, Seymour J, et al. Effect of a home exercise video programme in patients with chronic obstructive pulmonary disease. J Rehabil Med 2009; 41: 195-200.

Liu WT, Wang CH, Lin HC, et al. Efficacy of a cell phone-based exercise programme for COPD. Eur Respir 2008; 32: 651-659.

Deacon SI, Vincent EE, Greenhaff PL, et al. Randomized controlled trial of dietary creatine as an adjunct therapy to physical training in chronic obstructive pulmonary disease. Am J Respir Crit Care Med 2008; 178: 233-239.

Sewell L, Singh SJ, Williams JE, et al. Can individualized rehabilitation improve functional independence in elderly patients with COPD? Chest 2005; 128: 1194-1200.

Man WD, Polkey MI, Donaldson N, et al. Community pulmonary rehabilitation after hospitalisation for acute exacerbations of chronic obstructive pulmonary disease: randomised controlled study. BMJ 2004; 329: 1209.

Griffiths TL, Burr ML, Campbell IA, et al. Results at 1 year of outpatient multidisciplinary pulmonary rehabilitation: a randomised controlled trial. Lancet 2000; 355: 362-368.

Albores J, Marolda C, Haggerty M, et al. The use of a home exercise program based on a computer system in patients with chronic obstructive pulmonary disease. J Cardiopulm Rehabil Prev 2013; 33: 47-52.

Ringbaek T, Martinez G, Lange P. The long-term effect of ambulatory oxygen in normoxaemic COPD patients: a randomised study. Chron Respir Dis 2013; 10: 77-84.

Linneberg A, Rasmussen M, Buch TF, et al. A randomised study of the effects of supplemental exercise sessions after a 7-week chronic obstructive pulmonary disease rehabilitation program. Clin Respir J 2012; 6: 112-119.

Altenburg WA, de Greef $\mathrm{MH}$, ten Hacken $\mathrm{NH}$, et al. A better response in exercise capacity after pulmonary rehabilitation in more severe COPD patients. Respir Med 2012; 106: 694-700.

Vest S, Moll L, Petersen M, et al. Results of an outpatient multidisciplinary COPD rehabilitation programme obtained in two settings: primary and secondary health care. Clin Respir J 2011; 5: 84-91.

Liddell F, Webber J. Pulmonary rehabilitation for chronic obstructive pulmonary disease: a pilot study evaluating a once-weekly versus twice-weekly supervised programme. Physiotherapy 2010; 96: 68-74.

Evans RA, Singh SJ, Collier R, et al. Generic, symptom based, exercise rehabilitation; integrating patients with COPD and heart failure. Respir Med 2010; 104: 1473-1481. 
316 Waterhouse JC, Walters SJ, Oluboyede Y, et al. A randomised $2 \times 2$ trial of community versus hospital pulmonary rehabilitation, followed by telephone or conventional follow-up. Health Technol Assess 2010; 14: $1-140$.

317 Ringbaek T, Brøndum E, Martinez G, et al. Rehabilitation in COPD: the long-term effect of a supervised 7-week program succeeded by a self-monitored walking program. Chron Respir Dis 2008; 5: 75-80.

318 Eaton T, Young P, Nicol K, et al. The endurance shuttle walking test: a responsive measure in pulmonary rehabilitation for COPD patients. Chron Respir Dis 2006; 3: 3-9. 